\title{
Pregnancy-induced humoral sensitization overrides $T$ cell tolerance to fetus-matched allografts in mice
}

\author{
Ashley N. Suah, ${ }^{1}$ Dong-Kha V. Tran, ${ }^{1}$ Stella H.W. Khiew, ${ }^{1}$ Michael S. Andrade, ${ }^{1}$ Jared M. Pollard, ${ }^{1}$ Dharmendra Jain, ${ }^{1}$ \\ James S. Young, ${ }^{1}$ Dengping Yin, ${ }^{1}$ Geetha Chalasani, ${ }^{2}$ Maria-Luisa Alegre, ${ }^{3}$ and Anita S. Chong \\ 'Department of Surgery, University of Chicago, Chicago, Illinois, USA. ²Department of Medicine, University of Pittsburgh, Pittsburgh, Pennsylvania, USA. ${ }^{3}$ Department of Medicine, University of Chicago, \\ Chicago, Illinois, USA.
}

\begin{abstract}
Immunological tolerance to semiallogeneic fetuses is necessary to achieving successful first pregnancy and permitting subsequent pregnancies with the same father. Paradoxically, pregnancy is an important cause of sensitization, resulting in the accelerated rejection of offspring-matched allografts. The underlying basis for divergent outcomes following reencounter of the same alloantigens on transplanted organs versus fetuses in postpartum females is incompletely understood. Using a mouse model that allows concurrent tracking of endogenous fetus-specific $T$ and $B$ cell responses in a single recipient, we show that semiallogeneic pregnancies simultaneously induce fetus-specific $\mathrm{T}$ cell tolerance and humoral sensitization. Pregnancy-induced antibodies, but not B cells, impeded transplantation tolerance elicited by costimulation blockade to offspring-matched cardiac grafts. Remarkably, in B cell-deficient mice, allogeneic pregnancy enabled the spontaneous acceptance of fetus-matched allografts. The presence of pregnancy-sensitized B cells that cannot secrete antibodies at the time of heart transplantation was sufficient to precipitate rejection and override pregnancyestablished T cell tolerance. Thus, while induction of memory B cells and alloantibodies by pregnancies establishes formidable barriers to transplant success for multigravid women, our observations raise the possibility that humoral desensitization will not only improve transplantation outcomes, but also reveal an unexpected propensity of multiparous recipients to achieve tolerance to offspring-matched allografts.
\end{abstract}

\section{Introduction}

Pregnancy is an example of a spontaneously acquired state of immunological tolerance, in this case to the semiallogeneic fetus. Studies into the mechanisms facilitating tolerance to the semiallogeneic fetus have determined that immune tolerance is most pronounced during the course of pregnancy and at the fetal-maternal interface (1-3). An array of tolerance mechanisms have been identified, including chemokine silencing in decidual stromal cells to prevent effector $\mathrm{T}$ cell recruitment (4) and the enrichment of placental FoxP3 ${ }^{+}$Tregs (5), decidual natural killer cells that are poorly cytolytic (6), decidual monocytes and $\gamma \delta \mathrm{T}$ cells that secrete the immunomodulatory cytokines IL-10 and TGF- $\beta$, monocytes that produce indoleamine 2,3-dioxygenase, and tolerogenic dendritic cells that express galectin-1 and macrophage inhibitory protein-1 (reviewed in refs. 2, 3). Expression of HLA-E and HLA-G by trophoblast cells further dampens responses by NK cells and T cells, and roles for $\mathrm{T}$ cell immunoglobulin and mucin domain containing-3 (TIM3), inducible costimulator ligand (ICOSL), and programmed cell death protein 1 (PD-1) in constraining $\mathrm{T}$ and $\mathrm{NK}$ cell responses

Authorship note: ANS, DKVT, and SHWK are co-first authors. MLA and ASC are co-senior authors.

Conflict of interest: The authors have declared that no conflict of interest exists. Copyright: (5) 2021, American Society for Clinical Investigation.

Submitted: May 27, 2020; Accepted: October 2, 2020; Published: January 4, 2021.

Reference information: / Clin Invest. 2021;131(1):e140715.

https://doi.org/10.1172/JCl140715. have also been reported (reviewed in refs. 2, 3, 7, 8). Importantly, some of these regulatory mechanisms extend systemically and are reinforced in secondary pregnancies (9-11). The disease activity in patients with rheumatoid arthritis decreasing spontaneously during pregnancy was recognized by Hench in 1938 (12), while Rowe et al. (10) reported a systemic increase in fetus-specific Tregs during secondary pregnancy that mediated reduced responses to Listeria monocytogenes infection and protection from fetal wastage.

Despite these multiple tolerance mechanisms involved in preserving the viability of the semiallogeneic fetus during primary and subsequent pregnancies, studies in the 1980s by Bell and Billington (13) reported that pregnancies in some maternal-paternal mouse strain combinations elicit a paternal-specific antibody response $(14,15)$. In the clinic, pregnancy is the second most important cause of allosensitization, which is quantified by the development of paternal HLA-specific antibodies $(16,17)$. Approximately $50 \%-84 \%$ of mothers develop these antibodies during pregnancy or in the first year after pregnancy, and the incidence and strength of the anti-HLA antibody response increases with each pregnancy $(18,19)$. As a result, it is more difficult for multiparous women with anti-HLA antibodies to find organ donors to whom they are not allosensitized and they are often precluded from receiving organs from male partners who are fathers of their offspring $(18,20)$. Thus, pregnancy contributes to a sex disparity in access to transplantation, and there is an urgent need to mitigate this disparity. We hypothesize that this can be achieved by understanding how pregnancy-induced tolerance to semiallogeneic fetus also results in sensitization to offspring-matched organ transplants. 
A

2W-OVA B/C के C57BL/6 (WT) of
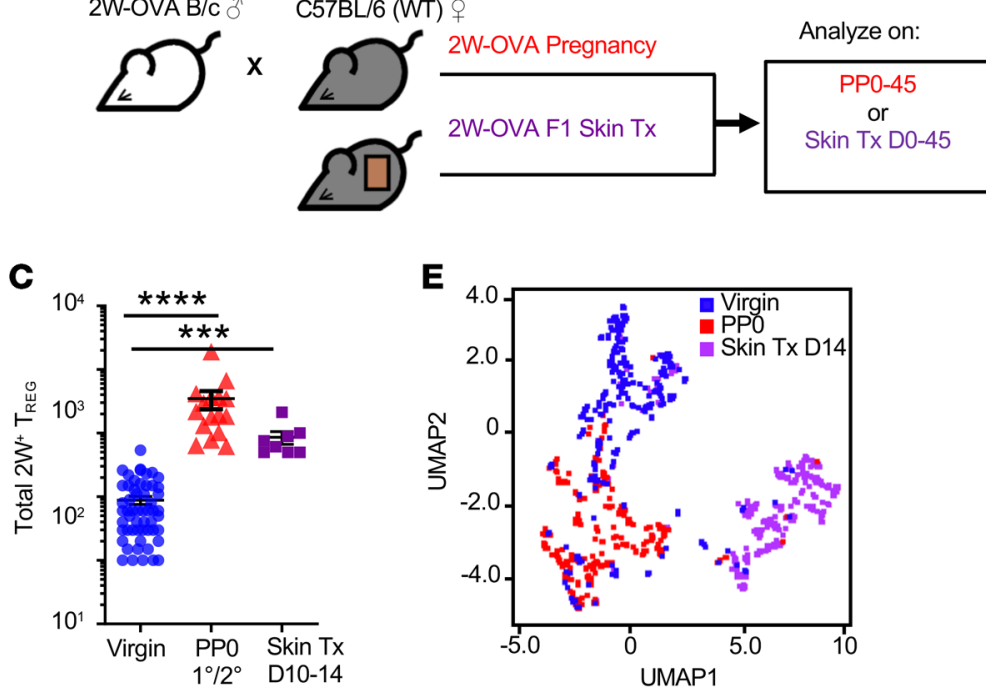

D
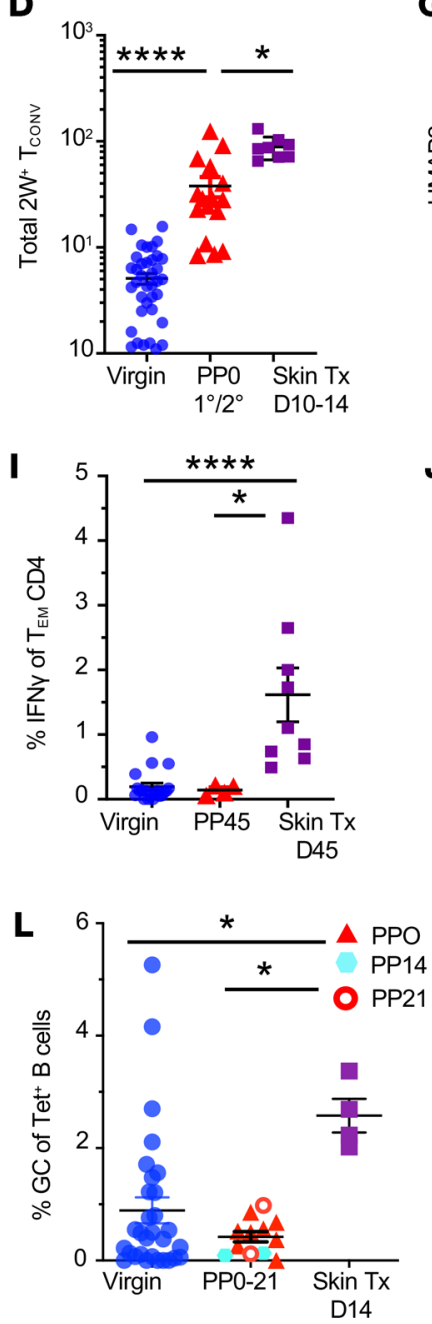

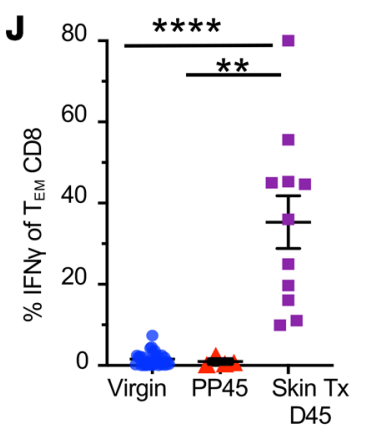

M

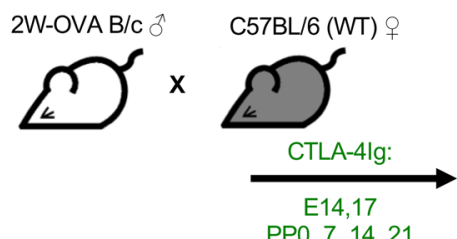

B

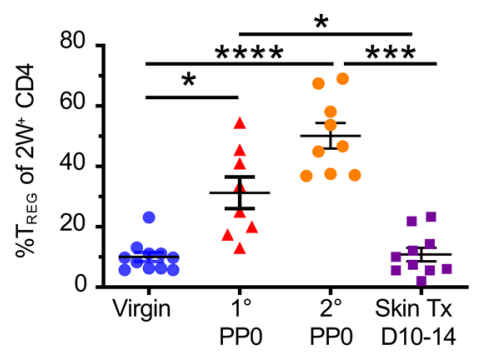

E
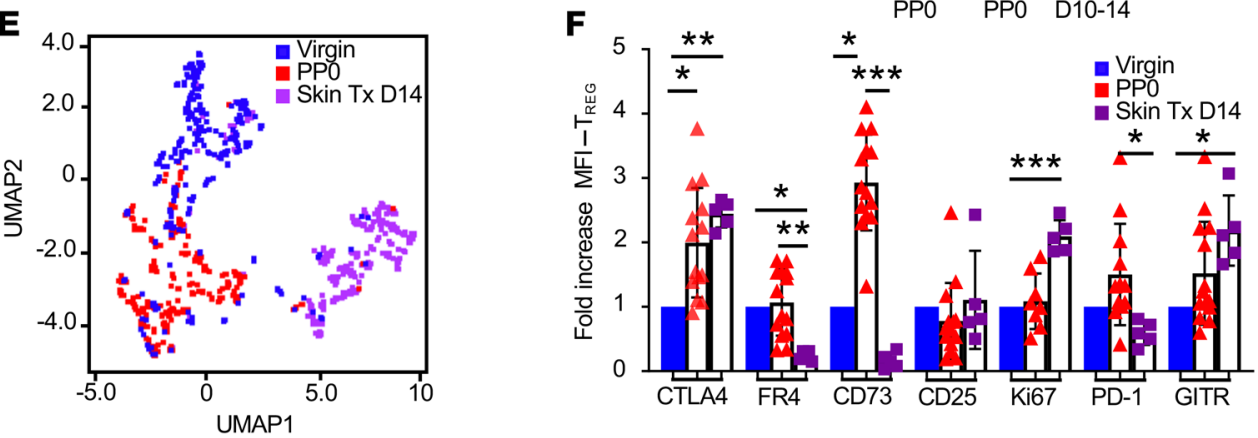

G

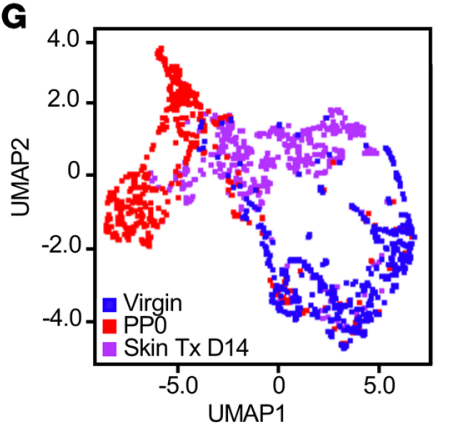

H

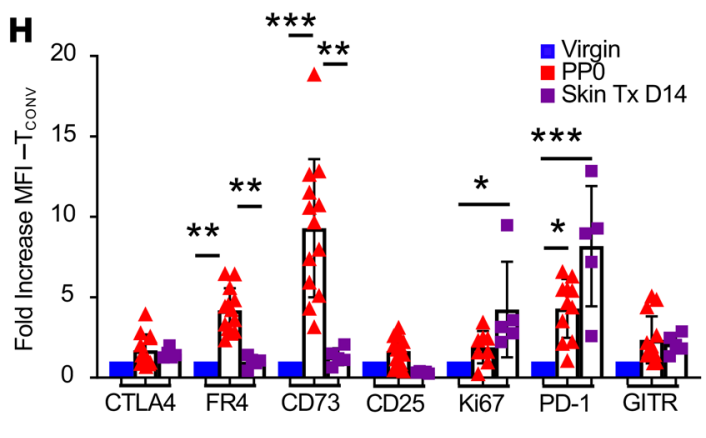

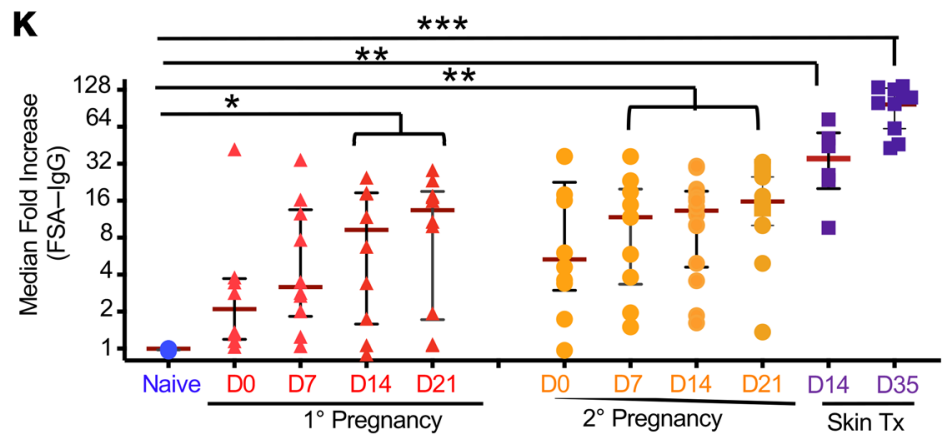

$\mathbf{N}$

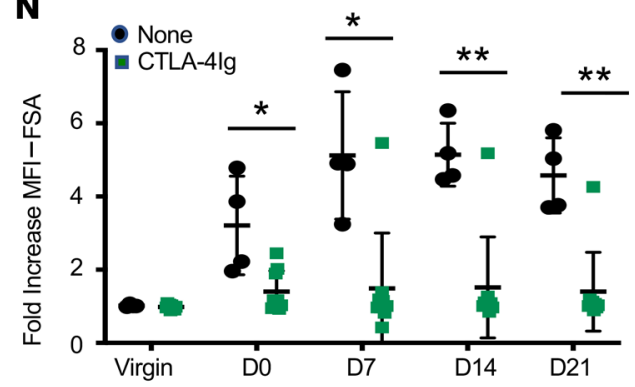


Figure 1. Allogeneic pregnancy elicits fetal-specific antibody responses despite induction of $T$ cell dysfunction. (A) Experimental design. Male transgenic 2W-OVA B/c were mated with female WT C57BL/6 to generate F1-expressing 2W-OVA, or female C57BL/6 were transplanted with 2W-OVA F1 skin. Spleen and LNs (inguinal, axillary, branchial) were harvested and analyzed on days PPO-PP45 after skin transplantation (skin Tx). (B) Percentages of Tregs of $2 \mathrm{~W}^{+} \mathrm{CD} 4^{+}$cells; $n=8-11$ /group. Data are pooled from 2 or more independent experiments. (C) Total number of $2 \mathrm{~W}: I A^{b}$ Tregs of CD4+ cells; $n=5$-27/group. (D) Total number of $2 \mathrm{~W}: \mathrm{IA}^{\mathrm{b}}$ Tconvs; $n=7-30 /$ group. (E) UMAP showing distinct clusters of Tregs from virgin, PPO, and skin-transplanted mice (POD14). (F) Fold increase MFI for Tregs from PPO and skin-transplanted mice (POD10-POD14) compared with naive/virgin; $n=5-13 /$ group. (C) UMAP demonstrating distinct cluster of Tconvs from virgin, PPO, and skin-transplanted mice at POD14. (H) Fold increase MFI for Tconvs from PPO and skin-transplanted (POD14) mice compared with naive/virgin; $n=5-13 /$ group. (I) Percentage of IFN- $\gamma$ of Tem CD4+ cells of virgin, approximately PP45, and skin-transplanted mice (approximately POD45); $n=4-18 /$ group. (J) Percentage of IFN- $\gamma^{+}$of Tem CD8 ${ }^{+}$cells; $n=4-29$. (K) Median fold increase of FSA (normalized to naive) of naive, primary pregnancy $\left(1^{\circ}\right)$ and secondary pregnancy $\left(2^{\circ}\right) \mathrm{PPO}$, PP7, PP14, and PP21 mice, skin-transplanted POD14 and POD35 mice; $n=$ 4-14/group. (L) Percentage of GC of Tet ${ }^{+} B$ cells of virgin, PPO, PP14, PP21, and skin-transplanted mice (POD14). $n=4-30 /$ group. (M) Experimental design. C57BL/6 female PP mice received CTLA-4lg ( $25 \mathrm{mg} / \mathrm{kg}$, i.p.) from E14 and were bled on a weekly interval. (N) Quantification of FSA from virgin or mice with postprimary pregnancy from PODO to POD21. Each dot represents an individual mouse; $n=4-10 /$ group. Data represent mean \pm SEM. $P$ values were determined by Kruskal-Wallis test with Dunn's post hoc test (B-D, $\mathbf{F}, \mathbf{H}-\mathbf{J}$, and $\mathbf{L}$ ) and Mann-Whitney $t$ test (K and $\mathbf{N})$. ${ }^{*} P<$ $0.05 ;{ }^{* *} P<0.01 ;{ }^{* * *} P<0.001 ;{ }^{* * *} P<0.0001$.

To investigate how semiallogeneic pregnancy alters responses to allografts sharing paternal alloantigens, we used female C57BL/6 mice mated with BALB/c males expressing the 2W1S-OVA transgene (2W-OVA.BALB/c) as a model of a ubiquitous membrane-expressed paternal antigen (21). With this model, Rowe et al. (10) reported that pregnancy results in a sustained expansion of maternal FoxP3 ${ }^{+}$Tregs with fetus specificity, while Kalekar et al. (22) reported that pregnancy induced anergic fetus-specific conventional $\mathrm{T}$ cells (Tconvs, Foxp3 $\mathrm{CD} 44^{\text {hi }} \mathrm{CD} 73^{\text {hi }} \mathrm{FR} 4^{\text {hi }}$ ) that were epigenetically poised to differentiate into induced Tregs. In our experiments, age-matched virgin or 4- to 6-week postpartum (PP) mothers were transplanted with 2W-OVA.F1 (C57BL/6 $\times$ BALB/c) heart allografts (HTx). Endogenous $\mathrm{CD} 4^{+}$and $\mathrm{CD}^{+} \mathrm{T}$ cells recognizing the $2 \mathrm{~W}$ or OVA antigen, respectively, were identified using $2 \mathrm{~W}: \mathrm{I}-\mathrm{A}^{\mathrm{b}}$ and $\mathrm{OVA}_{257-264}: \mathrm{K}^{\mathrm{b}}$ tetramers, while endogenous alloreactive $\mathrm{B}$ cells were visualized using a combination of $\mathrm{MHC} \mathrm{K}^{\mathrm{d}}, \mathrm{L}^{\mathrm{d}}$, and $\mathrm{I}-\mathrm{E}^{\mathrm{d}}$ tetramers (23-25). By leveraging this ability to concurrently track endogenous fetus-specific $\mathrm{T}$ and $\mathrm{B}$ cell responses in each transplant recipient, we show that semiallogeneic pregnancy simultaneously induced fetus-specific $\mathrm{T}$ cell tolerance and humoral sensitization. Fetal-specific antibodies prevented stable transplantation tolerance elicited by anti-CD154 and donor-specific splenocyte transfusion (CoB/DST). Furthermore, in the absence of $\mathrm{B}$ cells, semiallogeneic pregnancies induced $\mathrm{T}$ tolerance that facilitated the spontaneous acceptance of fetus-matched HTx. Thus, our observations underscore the complex regulatory/counterregulatory networks set up during pregnancy that have long-term impact on the immune responses to fetus-matched transplanted allografts.

\section{Results}

Semiallogeneic pregnancy elicits fetal-specific antibodies despite induction of $\mathrm{T}$ cell dysfunction. To characterize fetus-specific $\mathrm{T}$ and $\mathrm{B}$ cell responses to a semiallogeneic pregnancy, we mated C57BL/6 mice with $2 \mathrm{~W}$-OVA.BALB/c male mice, resulting in haplomismatched F1 fetuses expressing 2W-OVA; endogenous fetus-specific $\mathrm{CD}^{+}$Tregs and Tconvs were identified using $2 \mathrm{~W}: \mathrm{I}-\mathrm{A}^{\mathrm{b}}$ MHC class II tetramers (Figure 1A and Supplemental Figure 1; supplemental material available online with this article; https:// doi.org/10.1172/JCI140715DS1). Implantation of fetuses occurs on embryonic day 4-5 (E4-E5) after fertilization, and fetal antigen becomes systemically available to prime maternal T cells by E10 $(26,27)$; thus PP mice are exposed to developing semiallogeneic fetuses for approximately 10 days. 2W-OVA.F1 skin-grafts were examined on postoperative days 10-14 (POD10-POD14), around the day of acute rejection. We confirmed that primary pregnancy preferentially expanded $2 \mathrm{~W}: \mathrm{I}-\mathrm{A}^{\mathrm{b}}$ Tregs and that secondary pregnancy induced an even higher percentage of $2 \mathrm{~W}: \mathrm{I}-\mathrm{A}^{\mathrm{b}}$ Tregs, within the spleen and LNs harvested at days 0-3 PP (PPO-PP3) (Figure 1B). This increase in percentages of Tregs was the result of an approximately 35 -fold increase in the number of $2 \mathrm{~W}: \mathrm{I}-\mathrm{A}^{\mathrm{b}}$ Tregs at PPO-PP3 of primary or secondary pregnancy and a 7-fold increase in $2 \mathrm{~W}: \mathrm{I}-\mathrm{A}^{\mathrm{b}}$ Tconvs (Figure 1, C and D). In contrast, sensitization with $\mathrm{F} 1$ skin grafts resulted in a 9-fold increase in numbers of $2 \mathrm{~W}: \mathrm{I}-\mathrm{A}^{\mathrm{b}}$ Tregs and a $17-$ fold increase in $2 \mathrm{~W}: \mathrm{I}^{-} \mathrm{A}^{\mathrm{b}}$ Tconvs compared with naive, resulting in a net $40 \%$ reduction in the percentage of Tregs of $2 \mathrm{~W}: \mathrm{I}-\mathrm{A}^{\mathrm{b}} \mathrm{CD} 4^{+} \mathrm{T}$ cells (Figure 1, B and D).

We next assessed by flow cytometry the expression of 7 markers that have been implicated in Treg function (Supplemental Figures 2 and 3) (28-30) and then performed analyses with uniform manifold approximation and projection (UMAP) (Figure $1 \mathrm{E}$ ), an algorithm for dimension reduction and construction of topological spaces. These studies demonstrate that the Tregs activated by pregnancy, examined on PPO, were indeed different from those activated by skin rejection. When compared with naive 2W:I-A $A^{\mathrm{b}}$ Tregs, PPO Tregs exhibited increased expression of CTLA-4, a coinhibitory molecule, and CD73, a cell-surface enzyme that mediates the hydrolysis of ATP and ADP into antiinflammatory adenosine (31-33). 2W:I-A ${ }^{\mathrm{b}}$ Tregs activated by 2W-OVA-F1 skin grafts at POD10-POD14 significantly upregulated CTLA-4, GITR, and Ki67, but did not upregulate CD73 (Figure 1F). Thus, Tregs activated by semiallogeneic pregnancy were phenotypically distinct from those activated by offspring-matched skin allografts.

UMAP analysis also indicated that pregnancy induced an activation phenotype in $2 \mathrm{~W}: \mathrm{I}-\mathrm{A}^{\mathrm{b}}$ Tconvs distinct from Tconvs activated by skin sensitization (Figure 1G). PP Tconvs, but not those after skin transplant, significantly upregulated expression of the FR4 folate receptor and CD73, while Tconvs from skin-rejecting females upregulated Ki67 instead (Figure 1H). PD-1 was significantly upregulated on Tconvs in both PP and skin-rejection females (Figure 1H). Because PP Tconvs (Supplemental Figure 3) uniquely exhibited an FR $4{ }^{\text {hi }} C D 73^{\text {hi }}$ phenotype consistent with anergy (22), we tested to determine whether PP Tconvs were functionally defective. T cells were stimulated with T cell-depleted 2W-OVA.F1 splenocytes, and the percentages of IFN- $\gamma^{+}$of $\mathrm{CD}^{+}$and $\mathrm{CD}^{+} \mathrm{T}$ cells with effector memory phenotype (Tem: $\mathrm{CD} 44^{+} \mathrm{CD} 62 \mathrm{~L}^{-}$) were enumerated (Sup- 
plemental Figure 4). Mice that rejected 2W-OVA.F1 skins and were examined on approximately day 45 after skin transplant had significantly increased frequencies of donor-specific IFN- $\gamma$-producing $\mathrm{CD}^{+}$and $\mathrm{CD} 8^{+} \mathrm{T}$ cells compared with naive mice (Figure 1 , I and $\mathrm{J})$. In contrast, mice at approximately PP45 did not, suggesting that, despite acquiring the Tem phenotype, fetus-specific (BALB/c) $\mathrm{T}$ cells had not acquired the ability to produce IFN- $\gamma$.

We next tested to determine whether semiallogeneic pregnancy elicits fetus-specific antibody (FSA) response. We show that primary PP mice indeed had modestly elevated FSA at PP7PP21, compared with high levels of donor-specific antibody (DSA) observed in skin allograft recipients (Figure $1 \mathrm{~K}$ and Supplemental Figure 5A). Notably, FSA levels remained increased in secondary pregnancy, with a higher percentage of PP females having elevated FSA during secondary compared with primary pregnancies (Figure 1K and Supplemental Figure 5B). Similar to what occurred with DSA after skin transplantation, FSA IgG were predominantly of the IgG2c subclass (Supplemental Figure 5C) and included IgG specific for 2W-OVA (Supplemental Figure 5D). Overall, these observations are consistent with clinical reports showing that the percentage of women with IgG antibodies specific for fetusmatched HLA increases with the number of pregnancies with the same male partner (16). Alloreactive B cells were identified using the combination of $\mathrm{K}^{\mathrm{d}}, \mathrm{L}^{\mathrm{d}}$, and $\mathrm{I}-\mathrm{E}^{\mathrm{d}}$ tetramers, as we previously reported (Supplemental Figure 6) (23-25). Interestingly, the FSA response was not associated with a detectable germinal center (GC) response in the uterine-draining LNs, as there was no significant increase in the percentage of donor-reactive $\mathrm{B}$ cells with a GC $\left(\mathrm{Fas}^{+} \mathrm{GL} 7^{+}\right)$phenotype at PPO, PP14, or PP21 (Figure 1L). Nevertheless, treatment with CTLA-4Ig to block CD28:B7 interactions (34) from E14 through PP21 prevented the development of fetus-specific IgG (Figure 1, M and N). Collectively, these data suggest that a semiallogeneic pregnancy elicits $\mathrm{T}$ cell-dependent but GC-independent FSA responses, despite the induction of fetus-specific Tregs and Tconv dysfunction.

Semiallogeneic pregnancy antagonizes the induction of stable tolerance to offspring-matched allografts. The observation of split functional outcomes of fetal-specific adaptive responses, with $\mathrm{T}$ cell tolerance but humoral sensitization, prompted us to test to determine whether PP C57BL/6 females would be more or less resistant to the induction of transplantation tolerance by $\mathrm{CoB} /$ DST. To answer this question, PP females were rested for 45-60 days, then transplanted with a 2W-OVA.F1 HTx (Figure 2A). Tolerance was induced with anti-CD154 administered on POD0, POD7, and POD14 and BALB/C DST on PODO. In virgin or PP females that experienced syngeneic pregnancies, this tolerogenic regimen resulted in long-term graft acceptance of 2W-OVA.F1 HTx (Figure 2B). In contrast, PP females that experienced semiallogeneic pregnancies were resistant to tolerance induction to fetus-matched HTx, as the majority $(\geq 60 \%)$ of cardiac allografts completely stopped beating by POD60. Notably, semiallogeneic skin-sensitized recipients rapidly rejected 2W-OVA.F1 HTx by POD8, suggesting the quality of sensitization by pregnancy was distinct from skin sensitization.

Because anti-CD154 in combination with DST is not a clinically approved therapy, we also tested the effect of semiallogeneic pregnancy on subsequent immunosuppression with CTLA-
4Ig (Figure 2C). A high-affinity mutant of CTLA-4Ig, belatacept, has been approved as prophylaxis for rejection in kidney transplant recipients (35), and short-term treatment with CTLA-4Ig (administered on POD0, POD2, POD4, POD7, and POD14) was able to promote long-term 2W-OVA.F1 HTx acceptance in virgin C57BL/6 recipients. In PP recipients, 2W-OVA.F1 HTx survival under CTLA-4Ig was significantly reduced (compare red and blue lines; Figure 2C).

To determine whether the resistance to CoB-induced tolerance was due to pregnancy-primed graft-specific T cells, we examined the 2W-OVA T cell response to 2W-OVA.F1 HTx \pm CoB/DST. Consistent with previous reports $(10,22)$, virgin tolerant recipients receiving $\mathrm{CoB} / \mathrm{DST}$ exhibited significant increases in the percentages of $2 \mathrm{~W}: \mathrm{I}-\mathrm{A}^{\mathrm{b}}$ Tregs on POD30 or later. This increase in percentage was due to a modest preferential increase in the total number of 2W:I-A $\mathrm{A}^{\mathrm{b}}$ Tregs over Tconvs (Figure 2, D-F). Notably, despite resistance to CoB-induced tolerance, PP mice had comparable increases in the frequency of $2 \mathrm{~W}: \mathrm{I}-\mathrm{A}^{\mathrm{b}}$ Tregs, also due to a preferential increase in Tregs and a decrease in Tconvs. Furthermore, the MFI of 2W:I$\mathrm{A}^{\mathrm{b}}$ binding on Tregs was significantly increased in PP recipients of 2W-OVA.F1 HTx plus CoB/DST compared with virgin recipients or pre-HTx PP mice (Supplemental Figure 7), consistent with a higher avidity recall Treg response. In contrast, mice first sensitized by 2W-OVA.F1 skin grafts followed by 2W-OVA.F1 HTx plus CoB/DST did not exhibit increases in the total number of $2 \mathrm{~W}: \mathrm{I}-\mathrm{A}^{\mathrm{b}}$ Tconvs and Tregs nor increases in the percentages of Tregs of $2 \mathrm{~W}: \mathrm{I}-\mathrm{A}^{\mathrm{b}} \mathrm{T}$ cells (Supplemental Figure 8, A-C). Additionally, these Tregs did not exhibit an increase in MFI of $2 \mathrm{~W}: \mathrm{I}^{-} \mathrm{A}^{\mathrm{b}}$ binding (Supplemental Figure 7). Thus, our observations confirm and extend the findings of Rowe et al. (10) demonstrating that semiallogeneic pregnancy-induced memory Tregs are capable of responding to fetus-matched heart allografts, whereas memory Tregs induced by skin-graft rejection are distinct and exhibit reduced accumulation upon recall with fetus-matched HTX plus CoB/DST.

Comparable numbers of $2 \mathrm{~W}: \mathrm{I}-\mathrm{A}^{\mathrm{b}}$ Tconvs observed in virgin, $\mathrm{PP}$, and skin rejection-sensitized mice receiving 2W-OVA.F1 HTx plus $\mathrm{CoB} / \mathrm{DST}$ prompted us to further test to determine whether $\mathrm{BALB} / \mathrm{c}$-specific $\mathrm{CD} 4^{+} \mathrm{T}$ cells were functionally distinct. To this end, we quantified the allogeneic $\mathrm{CD}^{+} \mathrm{T}$ cell IFN- $\gamma$ response upon stimulation with $\mathrm{T}$ cell-depleted splenocytes from $2 \mathrm{~W}$-OVA. F1 mice. The frequencies of IFN- $\gamma$-producing CD $4^{+} \mathrm{T}$ cells in virgin/naive mice and in semiallogeneic PP females receiving HTx plus CoB/DST were comparable (Figure $2 \mathrm{G}$ ). In contrast, mice sensitized by 2 W-OVA F1 skin grafts already exhibited increased percentages of donor-specific IFN- $\gamma$-producing $\mathrm{CD}^{+} \mathrm{T}$ cells prior to HTx and these remained elevated after HTx plus CoB/ DST (Supplemental Figure 8D). Collectively, these data suggest that pregnancy-primed Tconvs exhibited a sustained inability to secrete IFN- $\gamma$ despite acquiring a Tem phenotype and succumbing to $\mathrm{CoB} / \mathrm{DST}$-resistant HTx rejection.

We next tested to determine whether pregnancy-primed fetus/ donor-specific $\mathrm{CD}^{+} \mathrm{T}$ cell responses were controlled similarly to $\mathrm{CD}^{+}{ }^{+}$Tconv responses in PP recipients of HTx plus CoB/DST. We quantified the accumulation of OVA: $\mathrm{K}^{\mathrm{b}} \mathrm{CD} 8^{+} \mathrm{T}$ cells (Supplemental Figure 9) to show that 2W-OVA.BALB/c $\times$ C57BL/6 pregnancy induced a significant increase in the number of OVA: $\mathrm{K}^{\mathrm{b}} \mathrm{CD} 8^{+}$ $\mathrm{T}$ cells (Figure 2H). Following 2W-OVA.F1 HTx plus CoB/DST, 
A

\section{W-OVA B/c ô $\quad$ C57BL/6 (WT)}
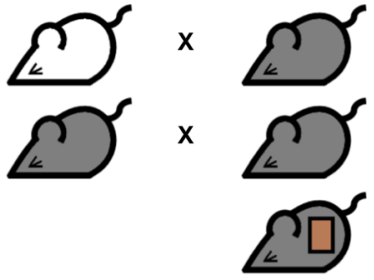

B

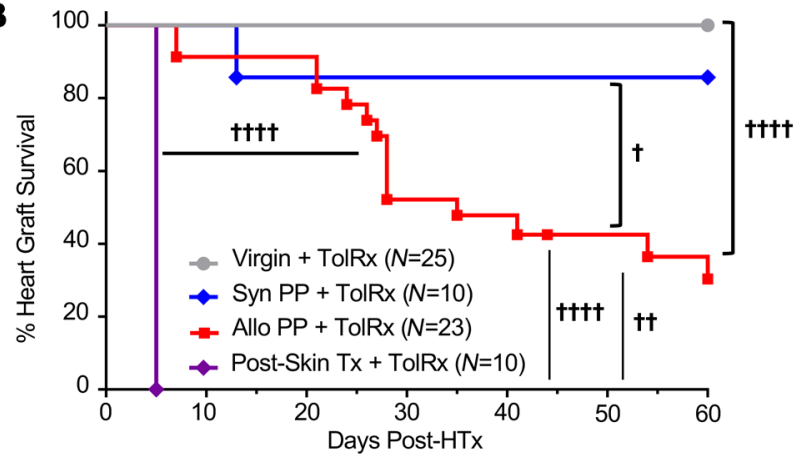

2W-OVA F1 (B/C X B6) HTX

+ TolRx (aCD154 + DST) OR + CTLA4lg
C

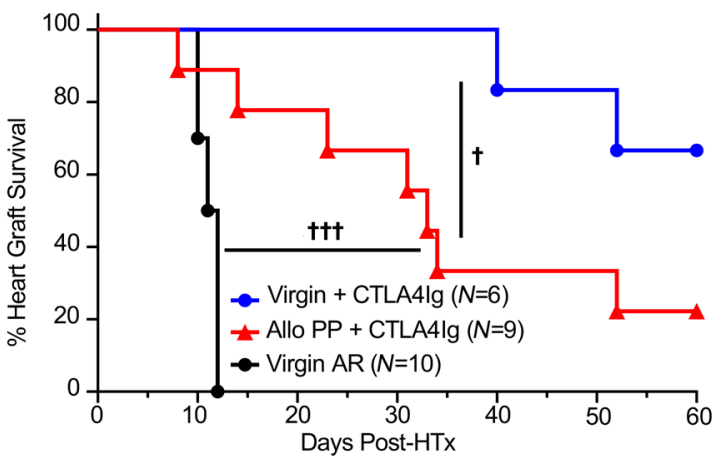

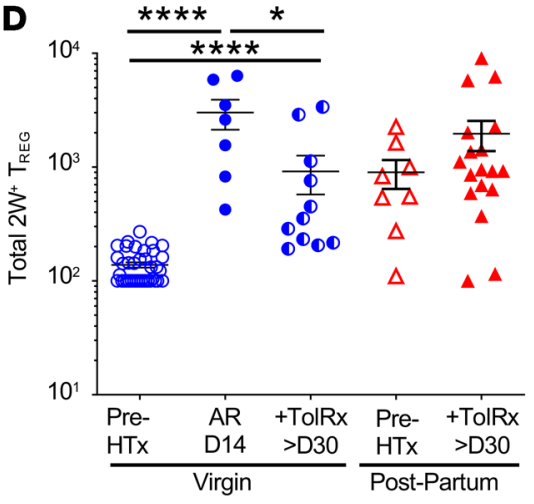

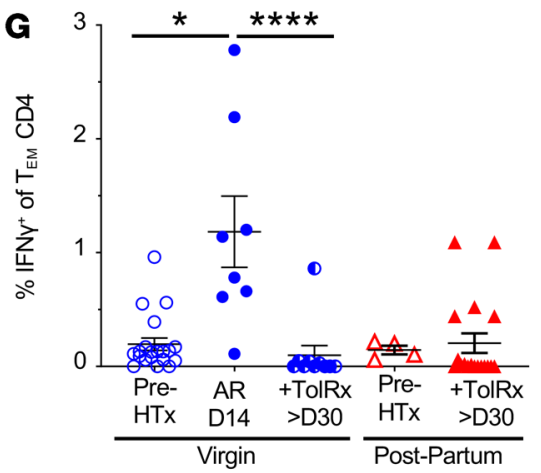

E

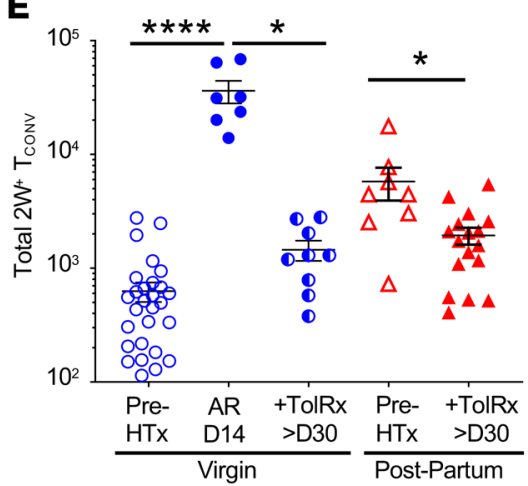

H

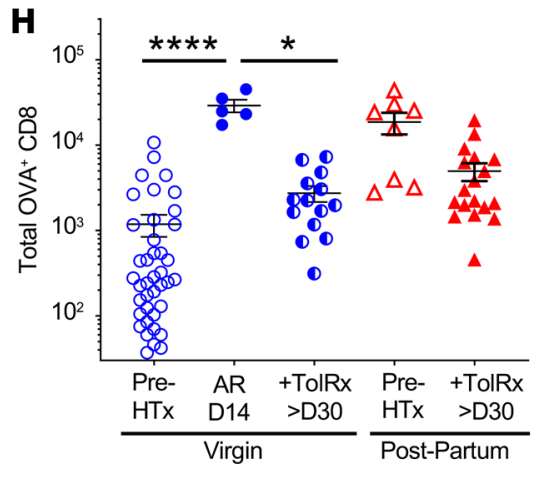

D
$\mathbf{F}$
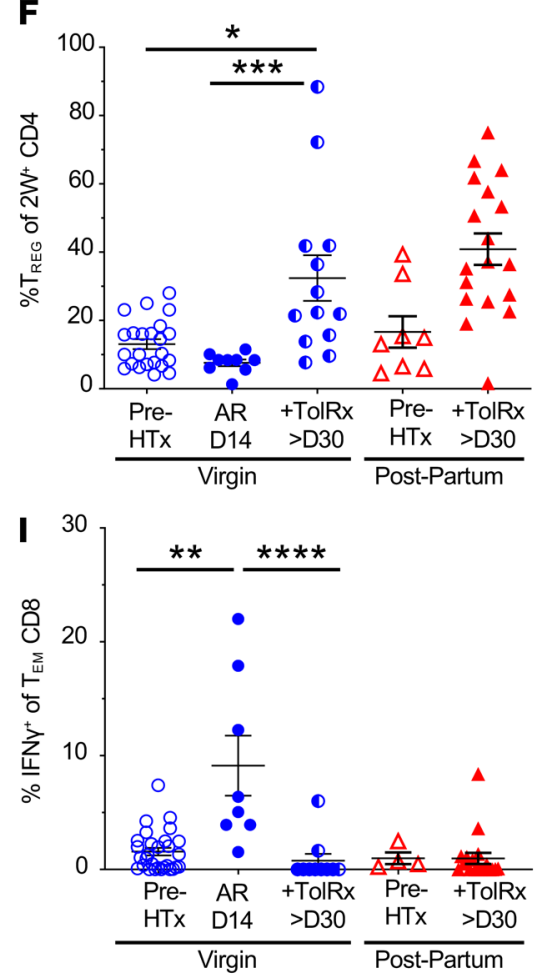

Figure 2. Allogeneic pregnancy induces resistance to transplantation tolerance despite allogeneic $\mathbf{T}$ cell dysfunction. (A) Experimental design. Male 2W-OVA.BALB/C were mated with female C57BL/6 to generate allogeneic F1-expressing 2W-OVA (allogeneic pregnancy), or male C57BL/6 were mated with female C57BL/6 to generate syngeneic F1 (syngeneic pregnancy), or female C57BL/6 mice were transplanted with 2W-OVA.F1 (BALB/C $\times$ C57B6) skin graft. After resting for 45-60 days, PP or skin-transplanted mice received 2W-OVA.F1 heart transplants and were treated with CoB/DST to induce tolerance (TolRx), or CTLA-4Ig on PODO, POD2, POD4, and POD7 after HTx. (B) Percentage of heart graft survival; $n=10-25 /$ group. ${ }^{\dagger} P<0.05$; ${ }^{+t} P<0.01$; ${ }^{t+t} P<0.0001$, log-rank test. (C) Percentage of heart graft survival, including acutely rejecting (AR) virgin controls: $n=6$-10/group. ${ }^{+} P<0.05$; ${ }^{+t+} P<0.001$, log-rank test. Spleens and inguinal, axillary, and brachial LNs were harvested from indicated mice on POD $\geq 30$. (D) Total number of 2W:IA $\mathrm{B}$ Tregs; $n=7-38 / g$ roup. (E) 2W:IA $A^{\mathrm{b}}$ Tconvs; $n=7-30 /$ group. (F) Percentage of Tregs of 2W:IA ${ }^{\mathrm{b}}$ CD4 ${ }^{+}$cells; $n=8-23 /$ group. (C) Percentage of IFN- $\gamma^{+}$of Tem CD4 ${ }^{+}$cells; $n=4-20 /$ group. (H) Total number of $\mathrm{OVA}^{+}$of CD8 ${ }^{+}$cells; $n=5-40 /$ group. (I) Percentage of IFN- $\gamma^{+}$of Tem CD8 ${ }^{+}$cells; $n=4-29 /$ group. Pre-HTx data are from Figure 1 , I and J. Data are pooled from 2 or more independent experiments and represent mean $\pm \mathrm{SEM} .{ }^{*} P<0.05$; ${ }^{* *} P<0.001$; ${ }^{* * *} P<0.0001$, Kruskal-Wallis test with Dunn's post hoc test or Mann-Whitney $t$ test $(\mathbf{D}-\mathbf{I})$. Data for the Pre-HTx groups in $\mathbf{G}$ and $\mathbf{H}$ are from Figure 1 , I and J, respectively. 

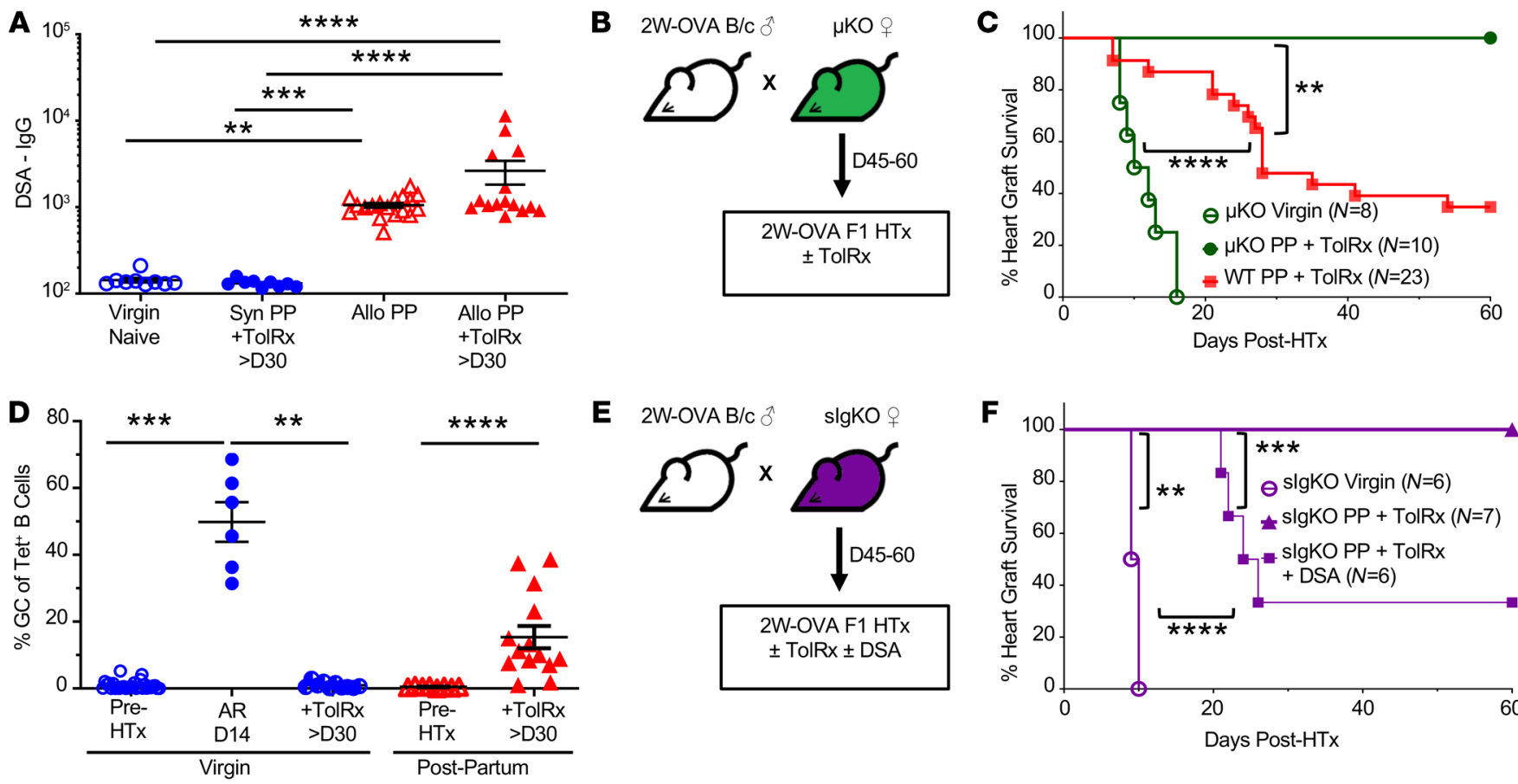

Figure 3. Donor-specific antibody resistance to CoB-induced transplant tolerance. (A) DSA-IgG (MFI) of virgin and allogeneic PP (PP45-PP60), syngeneic PP, and allogeneic PP 2W-OVA.F1 HTx and tolerance induction mice; $n=9-18 /$ group. (B) Experimental design. Male 2W-OVA.BALB/c were mated with $\mu$ KO. C57BL/6. PP $\mu$ KO females were rested 45-60 days, then received 2W-OVA.F1 hearts \pm CoB/DST (TolRx). (C) Percentage of heart graft survival; $n=8-23$ / group. Virgin $\mu \mathrm{KO}+$ TolRx vs. WT PP + TolRx (from Figure 2B), ${ }^{* * *} P<0.0001 ; \mathrm{PP} \mu \mathrm{KO}+$ TolRx vs. WT PP + TolRX (from Figure $2 \mathrm{~B}$ ); ${ }^{* *} P<0.01$ by log-rank test. (D) Percentage of GC (Fas $\left.{ }^{+} \mathrm{CL7}^{+}\right)$of Tet ${ }^{+} \mathrm{B}$ cells; $n=6-30 /$ group. ${ }^{*} P<0.01 ;{ }^{* * *} P<0.001 ;{ }^{* * *} P<0.0001$, Kruskal-Wallis test with Dunn's post hoc test (A and D). (E) Experimental design. Male 2W-OVA.BALB/c were mated with slgKO.C57BL/6. PP slgKO females were rested 45-60 days, then received 2W-OVA.F1 hearts and were treated with and without tolerance induction with CoB/DST (TolRx). (F) PP slgKO with HTx received a single dose (200 $\mu$ L, i.v.) of immune serum (DSA) at DO of HTx. Immune serum were pooled from D7-D21 2W-OVA.F1 skin-sensitized ( $n=3$; POD7-21) or pregnancy-sensitized mice ( $n=3$; PP7-21); $n=6-7 /$ group. ${ }^{* *} P<0.01 ;{ }^{* *} P<0.001 ;{ }^{* * *} P<0.0001$, log-rank test $(\mathbf{F})$. Data are pooled from 2 or more independent experiments and represent mean \pm SEM.

the total number of OVA: $\mathrm{K}^{\mathrm{b}} \mathrm{CD} 8^{+} \mathrm{T}$ cells in PP recipients did not increase further, but was instead significantly reduced to numbers comparable to those in tolerant virgin HTx plus CoB/DST recipients (Figure 2H). Similar results were observed for donor-specific IFN $-\gamma^{+} \mathrm{CD} 8^{+} \mathrm{T}$ cell responses (Figure 2I), which were comparably undetectable in virgin or PP recipients of 2W-OVA.F1 HTx plus CoB/DST (Figure 1J). In contrast, mice sensitized by 2W-OVA.F1 skin grafts followed by 2W-OVA F1 HTx plus CoB/DST harbored increased numbers of OVA: $\mathrm{K}^{\mathrm{b}} \mathrm{CD} 8^{+} \mathrm{T}$ cells and increased percentages of donor-specific IFN- $\gamma$-producing $\mathrm{CD} 8^{+} \mathrm{T}$ cells prior to $\mathrm{HTx}$, both of which remained elevated after HTx despite receiving $\mathrm{CoB} /$ DST (Supplemental Figure 8, E and F). Thus pregnancy-primed $\mathrm{CD}^{+} \mathrm{T}$ cells responses were also distinct from those primed by skin rejection and were controlled in PP recipients succumbing to $\mathrm{CoB} / \mathrm{DST}$-resistant rejection comparably to $\mathrm{CoB} / \mathrm{DST}$ tolerant virgin $\mathrm{HTx}$ recipients.

We conclude that the $\mathrm{CD} 4^{+} \mathrm{Tconv}$ and $\mathrm{CD} 8^{+} \mathrm{T}$ cell responses primed by semiallogeneic pregnancy were distinct from those sensitized by F1 skin rejection and that they were not escaping CoB/DST to mediate HTx rejection; this may explain the more modest rate of heart allograft rejection under COB/DST treatment compared with that of skin-transplanted recipients. We therefore hypothesized that pregnancy-sensitized humoral responses were the barrier to the induction of transplantation tolerance in PP HTx recipients.
Fetal-specific antibodies are necessary for pregnancy-acquired resistance to CoB-induced tolerance. In mice sensitized by an allograft, we previously reported that the presence of DSA at the time of donor-matched HTx prevented the induction of transplantation tolerance by CoB/DST $(36,37)$. The presence of detectable fetal-specific IgG at 45-60 days in PP females and also in PP recipients that received 2W-OVA.F1 HTx plus CoB/DST (Figure 3A) was consistent with the possibility that FSA was mediating pregnancy-induced resistance to transplantation tolerance. To directly test this hypothesis, we mated B cell-deficient $\mu \mathrm{KO}$.C57BL $/ 6$ females with $2 \mathrm{~W}$-OVA.BALB/c males and then used the PP $\mu \mathrm{KO}$ females as recipients of 2W-OVA.F1 HTx plus CoB/DST (Figure 3B). While virgin $\mu \mathrm{KO}$ females were able to acutely reject $2 \mathrm{~W}$-OVA.F1 HTx with kinetics similar to those of WT C57BL/6 females (Figure 2C and Figure $3 \mathrm{C}$ ), $\mathrm{PP} \mu \mathrm{KO}$ females receiving $\mathrm{CoB} / \mathrm{DST}$ treatment accepted 2W-OVA.F1 HTx (Figure 3C). These observations support our hypothesis that humoral sensitization by semiallogeneic pregnancy is the basis for the resistance to $\mathrm{CoB} / \mathrm{DST}$-induced transplantation tolerance in PP C57BL/6 mice.

While semiallogeneic pregnancy did not elicit a detectable GC response despite the development of FSA (Figure 1, K and L), alloreactive B cells in PP WT recipients of 2W-OVA.F1 HTx plus CoB/ DST were persistently $\mathrm{Fas}^{+} \mathrm{GL}^{+}$at POD of 30 or later, consistent with GC B cells. In contrast, B cells from virgin females tolerant 
A
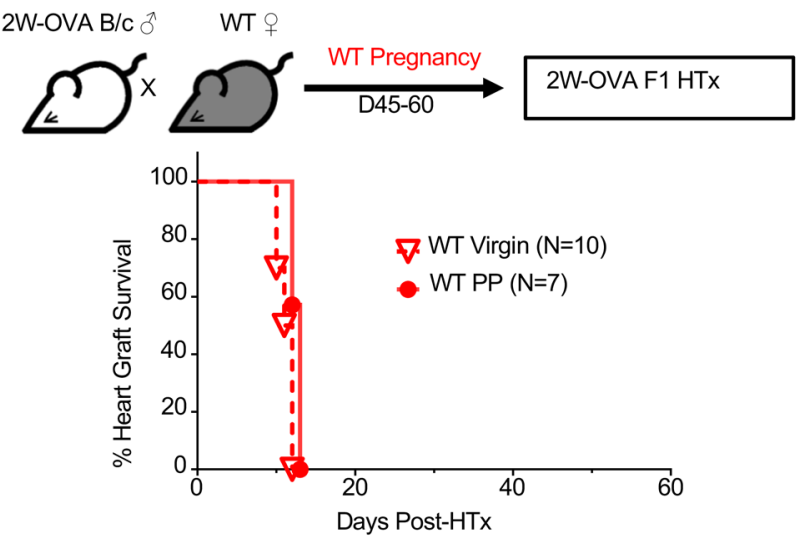

B $2 \mathrm{~W}-\mathrm{OVABB} / \mathrm{C} \hat{\circ} \mu \mathrm{KOO} O$

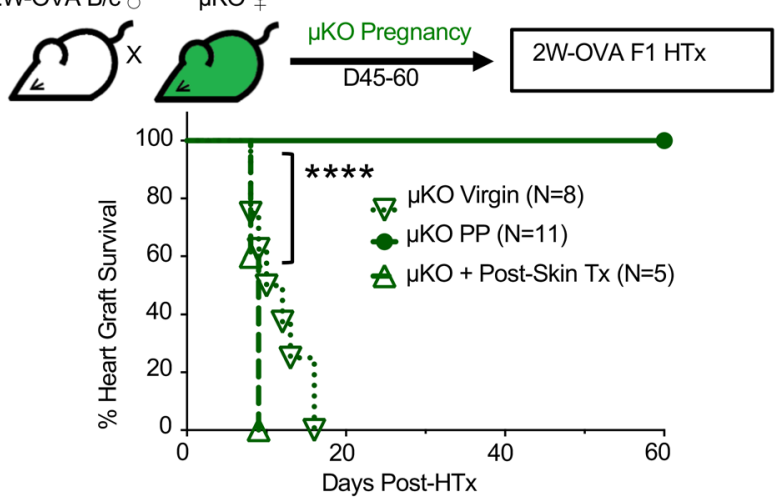

D
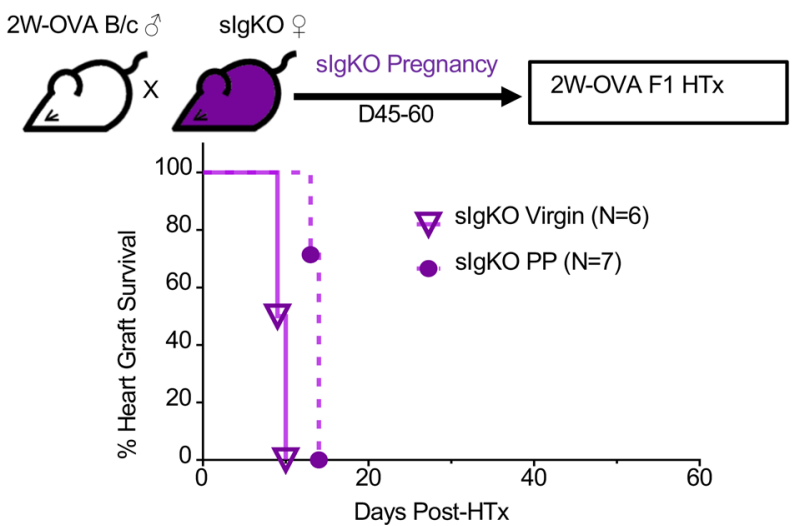

C

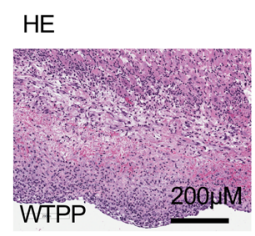

HE
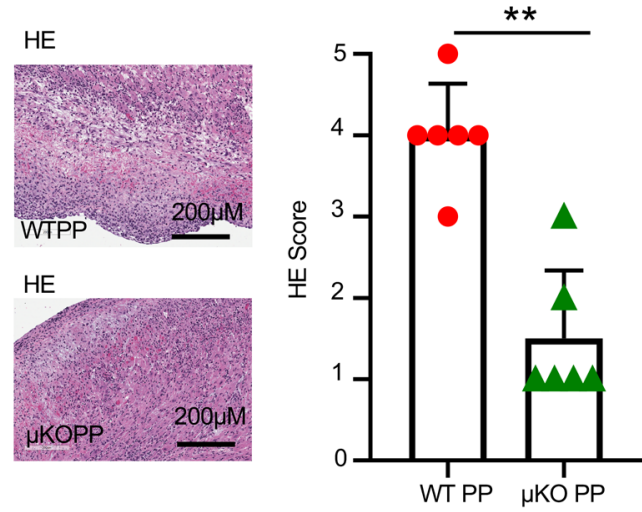

CD4

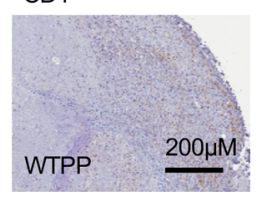

CD4
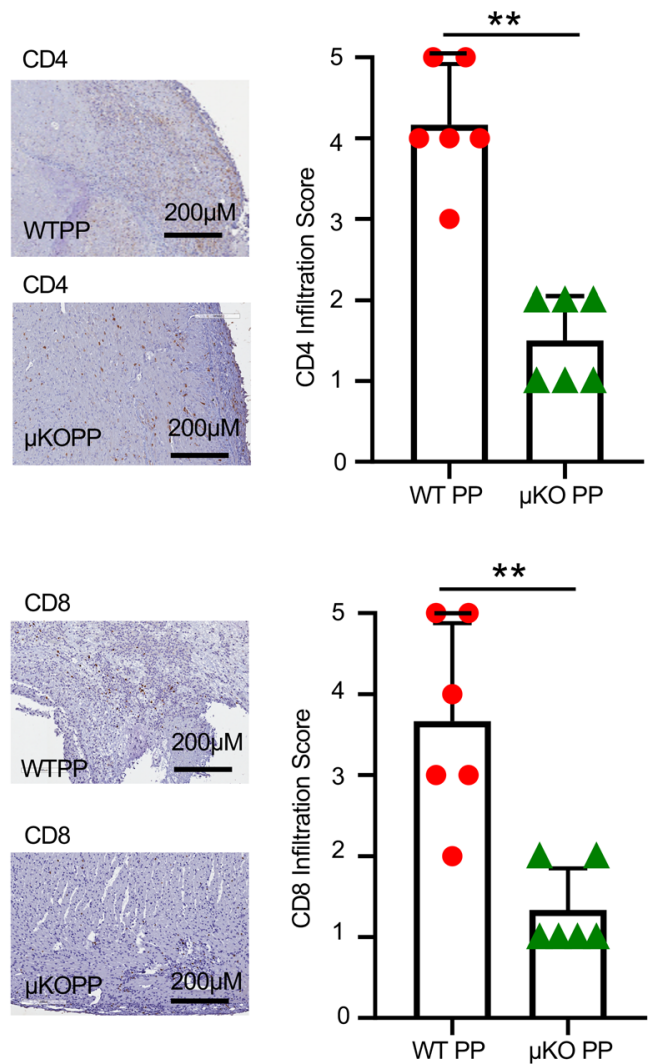

Figure 4. In the absence of B cells, allogeneic pregnancy induces spontaneous F1 heart graft acceptance. (A) Experimental design. Male 2W-OVA.BALB/C were mated with $\mathrm{C57BL} / 6$. After resting for 45-60 days, WT PP females were transplanted with 2W-OVA.F1 hearts without tolerance induction. Percentage of heart graft survival, virgin vs. PP WT; $n=7-10 /$ group. (B) Experimental design. Male 2W-OVA.BALB/c mated with $\mu \mathrm{KO}$.C57BL/6. $\mu \mathrm{KO}$ PP mice were rested for 45-60 days and then transplanted with 2W-OVA.F1 hearts without tolerance induction. Percentage of heart graft survival; $n=5-11 / g r o u p$, virgin $\mu \mathrm{KO}$ vs. PP $\mu \mathrm{KO}$; ${ }^{* * *} P<0.0001$, log-rank test. (C) Histology of allograft for WT PP and $\mu$ KO PP analyzed at day POD60 or later. Histology scores were based on abnormalities, decellularization, and cell infiltration for $\mathrm{H} \& \mathrm{E}$ stain and IHC staining for $\mathrm{CD} 4^{+}$and $\mathrm{CD} 8^{+}$cells. $n=6 / \mathrm{group}$. Original magnification, $\times 20$. Scale bars: $200 \mu \mathrm{m}$. (D) Experimental design. Male 2W-OVA.BALB/c were mated with slgKO.BL/6. After resting 45-60 days, PP slgKO females were transplanted with 2W-OVA.F1 hearts without tolerance induction. Percentage of heart graft survival; $n=6-7 /$ group. Data are pooled from 2 independent experiments and represent mean $\pm \mathrm{SEM} .{ }^{* *} P<0.01$, Mann-Whitney $t$ test. Heart graft survival data in virgin WT, $\mu$ KO, and slgKO mice are from Figure $2 \mathrm{C}$ and Figure $3, \mathrm{C}$ and $\mathrm{F}$, respectively.

to 2W-OVA.F1 HTx did not develop a detectable GC response and

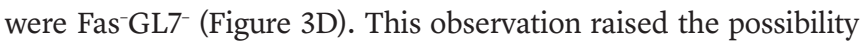
that PP B cells were not adequately controlled and might directly contribute to resistance to $\mathrm{CoB} / \mathrm{DST}$-induced tolerance, potentially serving as antigen-presenting or cytokine-producing cells. To test this possibility, we used sIgKO mice that lack the genes encoding secretory IgM and activation-induced deaminase (AID, Aicda), and thus their B cells cannot undergo affinity maturation or secrete antibodies of any isotype $(38,39)$ (Figure 3E). Virgin sIgKO mice rejected 2W-OVA.F1 HTx with kinetics similar to those of WT C57BL/6 mice. When treated with CoB/DST, PP sIgKO accepted the HTx allograft long term, similarly to PP $\mu \mathrm{KO}$ recipients (Figure $3 F)$. These observations indicate that PP B cells were not sufficient, and circulating FSA was necessary for preventing tolerance induc- 
A

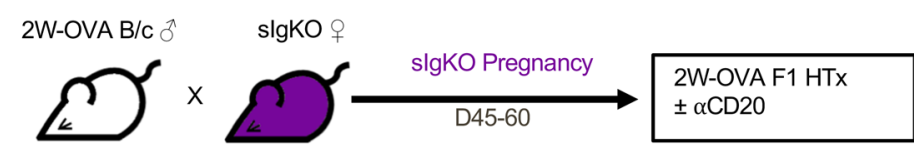

B

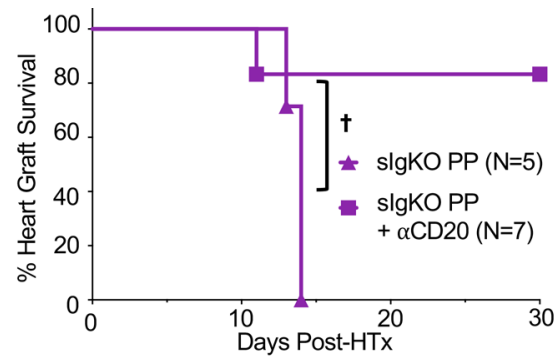

C

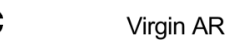

HE

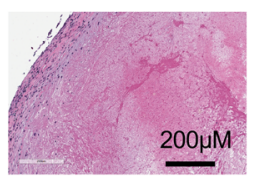

CD4

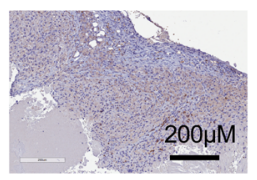

$\infty$

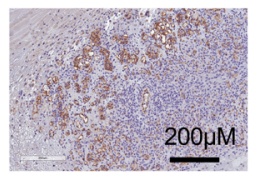

D

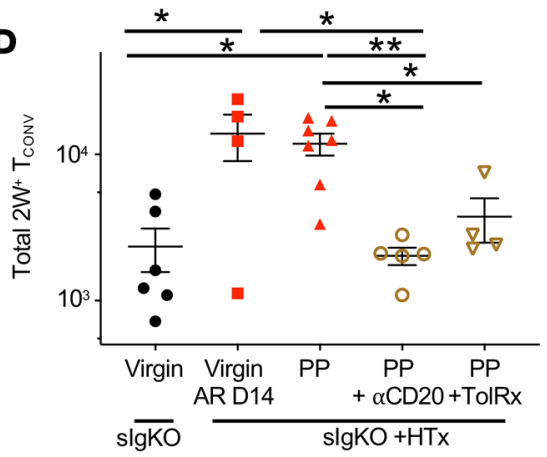

slgKO PP
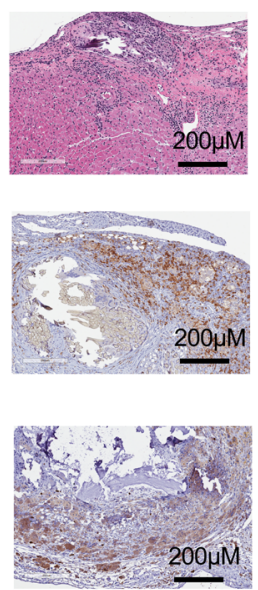

slgKO PP $+\alpha C D 20$
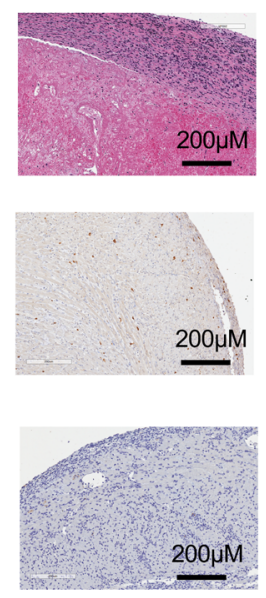

E

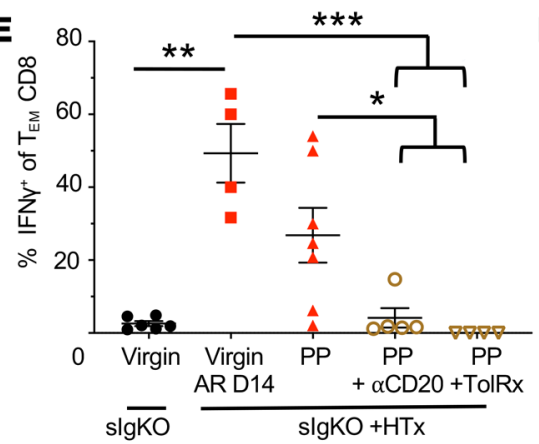

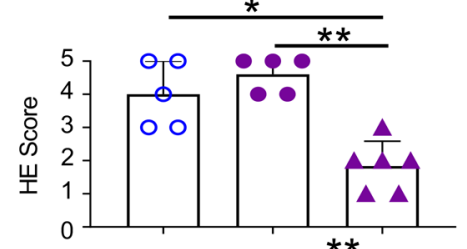

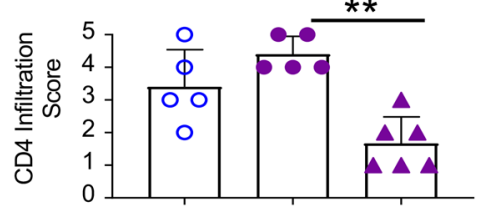

**

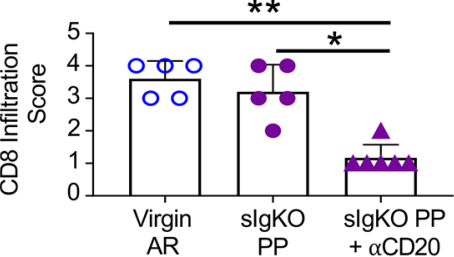

G
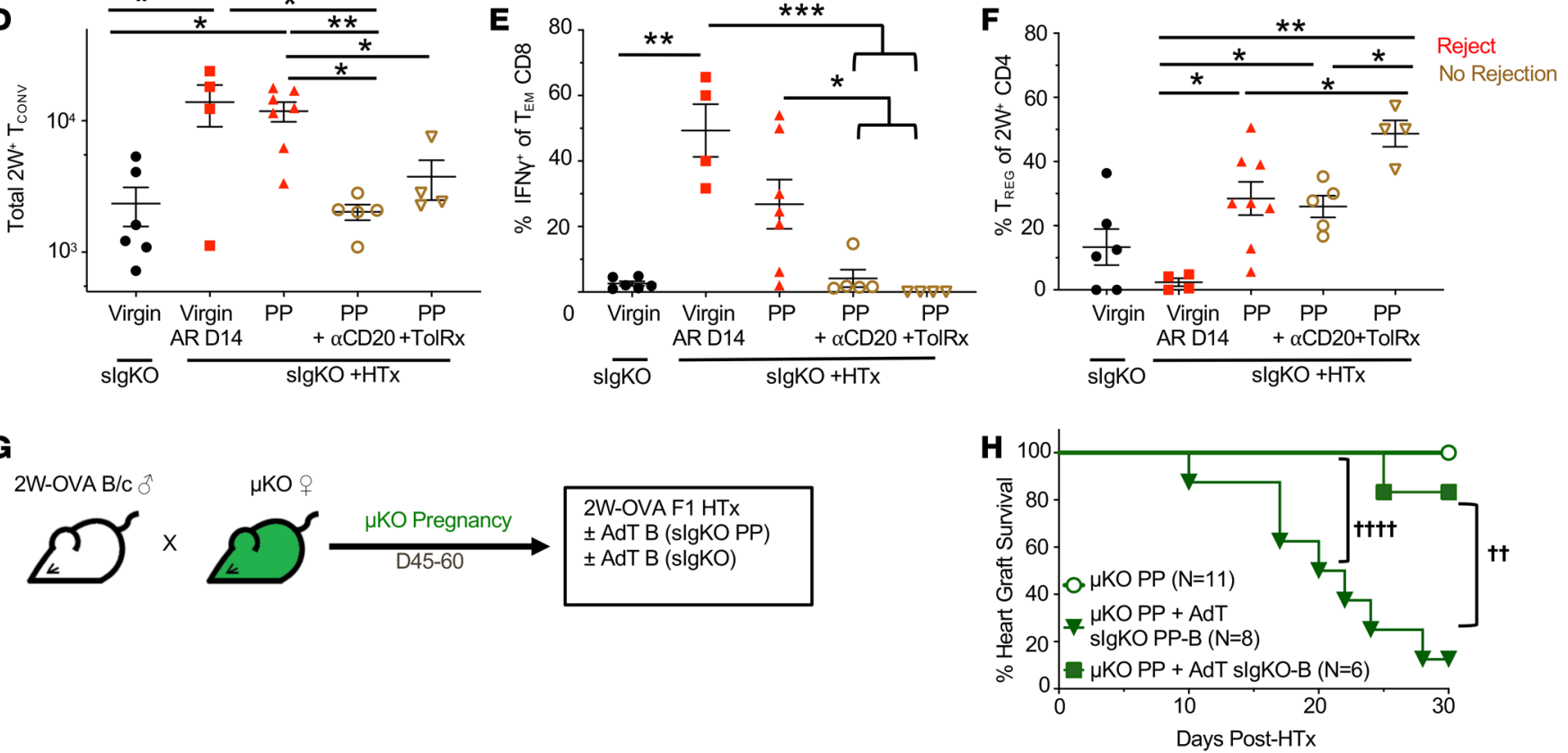

Figure 5. Pregnancy-sensitized B cells at the time of HTx overrides pregnancy-induced T cell tolerance. (A) Experimental design. Male 2W-OVA.BALB/c were mated with female slgKO.BL/6. After resting 45-60 days, slgKO PP females received $250 \mu$ g anti-CD20 antibody (i.v.) on days -1 and 7 after 2 W-OVA.F1 HTx. (B) Percentage of heart graft survival; $n=5-7 /$ group. ${ }^{\dagger} P<0.05$, log rank test. (C) Histology of allograft for virgin acute rejection (AR), PP slgKO, and PP slgKO with antiCD2O analyzed at POD30 or later. Graft scores were determined based on abnormalities, decellularization, and infiltration for H\&E stain and IHC for infiltrating $\mathrm{CD}^{+}$and CD8${ }^{+}$cells; $n=5$-6/group. Original magnification, $\times 20$. Scale bars: $200 \mu \mathrm{m}$. Spleens and inguinal, axillary, and brachial LN were harvested from indicated mice, and PP $+\mathrm{HTx}$ recipients were examined on day 30 after HTx. (D) Total number of $2 \mathrm{~W}^{+}$Tconvs; $n=4-7 /$ group. (E) Percentage of IFN- $\gamma^{+}$of Tem CD8 $8^{+}$cells; $n=$ 4-7 group. (F) Percentage of Tregs of $2 \mathrm{~W}^{+}$CD4+ cells; $n=4-8$ /group. (C) Experimental design. Male 2W-OVA.BALB/c were mated with female $\mu \mathrm{KO}$.C57BL/6. After resting for 45-60 days, $\mu$ KO PP females were transplanted with 2W-OVA.F1 heart graft with or without adoptive transfer of B cells purified from slgKO PP or virgin slgKO 1 day prior to heart transplantation. (H) Percentage of heart graft survival; $n=6-11 /$ group. ${ }^{+t} P<0.01$; ${ }^{+t+t} P<0.0001$, log-rank test. Heart graft survival data for slgKO PP and $\mu$ KO PP mice are from Figure 4, D and B, respectively. All data are pooled from 2 independent experiments and represent mean \pm SEM. ${ }^{*} P<0.05$; ${ }^{* *} P<0.01 ;{ }^{* *} P<0.001$, Kruskal-Wallis test with Dunn's post hoc 
tion. To test this, on the day of 2W-OVA.F1 HTx plus CoB/DST treatment, we transferred FSA-containing serum harvested from PP7-PP21 females ( $n=3$ ) or DSA-containing serum from skin-sensitized recipients (harvested on POD10-POD21; $n=3$ ). Transfer of graft-reactive antibody-containing serum was sufficient to restore HTx rejection (Figure $3 \mathrm{~F}$ ), supporting the conclusion that FSA/DSA at the time of HTx is sufficient to mediate resistance to CoB-mediated transplantation tolerance in PP sIgKO recipients.

Absence of B cells reveals pregnancy-induced $T$ cell tolerance to offspring-matched allografts. The induction of fetus-specific memory Tregs along with nonfunctional Tconvs and $\mathrm{CD} 8^{+} \mathrm{T}$ cell responses in PP HTx recipients raised the possibility that fetus-specific $\mathrm{T}$ cells might be tolerized to such an extent that PP mice spontaneously accept a fetus-matched HTx if B cells and FSA are absent. To investigate this, we transplanted OVA-2W.F1 HTx into virgin or $\mathrm{PP} W \mathrm{~T}$ or PP $\mu \mathrm{KO}$ females without any immunosuppression or tolerance-inducing regimen. As expected, WT virgin and PP females rejected OVA-2W.F1 HTx with comparable kinetics (Figure 4A) and virgin $\mu \mathrm{KO}$ females acutely rejected OVA-2W.F1 HTx with kinetics comparable to those of virgin or PP WT females (Figure 4B). Strikingly, PP $\mu \mathrm{KO}$ mice spontaneously accepted OVA-2W. F1 HTx. In contrast, $\mu \mathrm{KO}$ mice that were sensitized by $2 \mathrm{~W}$-OVA. F1 skin transplants rejected skin-matched HTx with slightly faster kinetics compared with virgin $\mu \mathrm{KO}$ mice, confirming the ability of $\mu \mathrm{KO}$ mice to generate productive memory $\mathrm{T}$ cell responses. Histology and immunohistochemistry confirmed that the rejection of allografts by virgin $\mu \mathrm{KO}$ was associated with $\mathrm{CD} 4^{+}$and $\mathrm{CD} 8^{+} \mathrm{T}$ cells, and lack of rejection correlated with significantly reduced $\mathrm{T}$ cell infiltration in PP $\mu \mathrm{KO}$ (Figure 4C). Collectively, these experiments reveal the ability of semiallogeneic pregnancy to induce a sustained and systemic state of fetus-specific T cell tolerance such that PP $\mu \mathrm{KO}$ mice were able to spontaneously accept a semiallogeneic heart graft transplanted 45-60 days after pregnancy, when $\mathrm{B}$ cells and donor-specific antibodies were absent. Nevertheless, pregnancy-induced $\mathrm{T}$ cell tolerance in $\mathrm{PP} \mu \mathrm{KO}$ mice was not able to induce the acceptance of 2W-OVA.F1 or 2W-OVA.B/6 skin grafts (Supplemental Table 1), consistent with the notion that skin transplants are more susceptible to rejection than heart allografts.

To determine whether the presence of B cells was sufficient or whether secreted antibodies were necessary to abrogate the pregnancy-induced tolerance observed in $\mathrm{PP} \mu \mathrm{KO}$ mice, we determined whether PP sIgKO mice were able to spontaneously accept OVA-2W. F1 HTx. As illustrated in Figure 4D, PP sIgKO acutely rejected OVA2W.F1 HTx with kinetics that were only modestly delayed compared with that of virgin sIgKO mice. Thus, the presence of B cells incapable of secreting antibodies is sufficient to prevent the spontaneous acceptance of an offspring-matched graft in PP $\mu \mathrm{KO}$ mice.

Pregnancy-sensitized $B$ cells at transplantation override $T$ cell tolerance to offspring-matched allografts. The presence of B cells in sIgKO mice, in theory, may have prevented the induction of T cell tolerance during semiallogeneic pregnancy. Alternatively, their presence may have permitted the development of $\mathrm{T}$ cell tolerance during pregnancy, but $\mathrm{T}$ cell tolerance was overridden by these $B$ cells at the time of HTx. Because most studies identifying the many mechanisms of pregnancy-induced $\mathrm{T}$ cell tolerance were performed in WT mice where B cells were present, we favored the latter possibility. We first tested to determine whether B cells were able to override pregnancy-induced T cell tolerance by depleting $B$ cells from PP sIgKO females at the time of HTx (Figure 5A). Treatment with anti-CD20 on POD0 significantly extended allograft acceptance in PP sIgKO females (Figure 5B), and the numbers of B cells in the spleen and LNs, including donor MHC-specific B cells, remained significantly lower than in WT C57BL/6 mice at the time of sacrifice at POD30 (Supplemental Figure 10). These observations suggest that the presence of B cells during pregnancy did not prevent the induction of fetus-specific $\mathrm{T}$ cell tolerance, but rather $\mathrm{T}$ cell tolerance was overridden by the presence of sIgKO B cells at the time of HTx. Furthermore, because sIgKO B cells are unable to produce antibodies, we hypothesized that these $\mathrm{B}$ cells were promoting HTx rejection by facilitating the activation of allograft-reactive T cells. Indeed, 2W-OVA.F1 HTx from PP sIgKO mice had $\mathrm{T}$ cell infiltration comparable to that of acutely rejected HTx in virgin mice, whereas HTx from PP sIgKO recipients depleted of B cells had significantly reduced $\mathrm{T}$ cell infiltrate (Figure $5 \mathrm{C}$ ).

To define the extent to which $\mathrm{B}$ cells in PP sIgKO recipients of 2W-OVA.F1 HTx were able to activate the donor-specific T cell response, we first quantified the $2 \mathrm{~W}: \mathrm{I}-\mathrm{A}^{\mathrm{b}} \mathrm{T}$ cells response on day 30 after HTx. Indeed, the total number of $2 \mathrm{~W}: \mathrm{I}^{-A^{\mathrm{b}}}$ Tconvs recovered from PP sIgKO recipients after 2W-OVA.F1 HTx was comparable to acute rejection in virgin sIgKO recipients (Figure 5D), and when $\mathrm{B}$ cells were depleted in PP sIgKO at the time of 2W-OVA.F1 HTx, the frequency of $2 \mathrm{~W}: \mathrm{I}-\mathrm{A}^{\mathrm{b}}$ Tconvs in PP sIgKO recipients was significantly reduced and was comparable to frequencies observed in tolerant PP sIgKO recipients treated with CoB/DST. These observations are consistent with $\mathrm{B}$ cells promoting donor-specific $\mathrm{CD} 4^{+}$ Tconvs responses in PP sIgKO recipients of HTx.

Likewise, the alloreactive IFN $-\gamma$ response in $\mathrm{CD}^{+} \mathrm{T}$ cells, which was markedly increased in PP sIgKO recipients of $2 \mathrm{~W}$-OVA. F1 HTx, was significantly reduced with B cell depletion and approached levels comparable to those of tolerant sIgKO HTx recipients treated with $\mathrm{CoB} / \mathrm{DST}$ (Figure $5 \mathrm{E}$ ). The decrease in donor-specific $\mathrm{CD}^{+}$IFN- $\gamma$ response upon B cell depletion was not associated with a significant reduction in the total number of OVA: $\mathrm{K}^{\mathrm{b}} \mathrm{CD} 8^{+} \mathrm{T}$ cells (Supplemental Figure 11). Taken together, these observations support the conclusion that B cells at the time of 2W-OVA.F1 HTx in PP sIgKO recipients were promoting donor-specific $\mathrm{CD}^{+} \mathrm{T}$ cell activation. Finally, the total number of 2W:I-A ${ }^{b}$ Tregs recovered after HTx in PP sIgKO recipients was not significantly altered with B cell depletion (Figure 5F). Collectively, these observations suggest that PP B cells at the time of F1 HTx were directly overriding graft-specific Tconv and CD8 ${ }^{+} \mathrm{T}$ cell tolerance, rather than preventing Treg expansion.

The sufficiency of PP B cells to override T cell tolerance was tested by isolating B cells from PP sIgKO mice and adoptively transferring them into PP $\mu \mathrm{KO}$ females 1 day before $2 \mathrm{~W}$-OVA.F1 HTx. Despite the inability to secrete antibodies, those PP B cells were able to restore acute rejection to $\mathrm{PP} \mu \mathrm{KO}$ recipients (Figure $5, \mathrm{G}$ and $\mathrm{H})$. In contrast, $\mathrm{B}$ cells from naive sIgKO B cells were not able to restore HTx rejection. These observations confirm that the presence of PP B cells during pregnancy did not affect the induction of fetus-specific $\mathrm{T}$ cell tolerance, but were necessary and sufficient at the time of transplantation to override pregnancy-induced $\mathrm{T}$ cell tolerance and the spontaneous acceptance of offspring-matched cardiac allografts. 


\section{Discussion}

Pregnancy remains an immunological paradox, whereby semiallogeneic pregnancy does not elicit the type of immunological memory observed following exposure to allografts, as it allows repeated successful semiallogeneic pregnancies with the same male partner. Yet in clinical transplantation, pregnancy is considered a highly sensitizing event, defined by the presence of antibodies directed at paternal HLA in multiparous females (40). The percentage of PP women presenting with FSA increases with multiparity $(18,19)$, and PP females harboring FSA that are also graft reactive tend to rapidly reject their allografts, secondary to antibody-mediated rejection (41). It is less clear whether $\mathrm{T}$ cell responses to offspring-matched allografts in PP females are also heightened.

To investigate how fetus-specific $\mathrm{T}$ and $\mathrm{B}$ cell responses generated during a prior allogenic pregnancy alter the immune response to an offspring-matched heart allograft, we used a preclinical mouse model of allogeneic mating that allowed endogenous fetal-specific $\mathrm{T}$ and $\mathrm{B}$ cells to be tracked longitudinally from early postparturition through the after HTx period. We confirmed that an induction of fetus-specific T cell dysfunction in PPO females was associated with a preferential expansion of $2 \mathrm{~W}: \mathrm{I}-\mathrm{A}^{\mathrm{b}}$ Tregs over Tconvs, an acquired expression by Tconvs of FR4 and CD73, markers of T cell anergy (22), and a sustained inability to produce IFN- $\gamma$ by Tconvs. In addition, PD-1 was upregulated in PP Tconvs and PD-1/PD-L1 interactions have been reported to be necessary for maintaining maternal $\mathrm{T}$ cell quiescence and averting fetal wastage (42). At PPO, Tregs exhibited increased expression of CD73 and CTLA-4, molecules that have been implicated in the function of Tregs $(22,29,33)$. Nevertheless, despite evidence of sustained fetus-specific $\mathrm{T}$ cell dysfunction, FSA was significantly increased in the PP period following semiallogeneic pregnancy and the kinetics of FSA development were congruent with those reported for women during pregnancy and in the PP period (43). Notably, we did not detect a GC B cell response during FSA development, but FSA production was blocked by CTLA-4Ig, suggesting that it is T cell dependent but GC independent.

The observation of split adaptive immune fates induced by semiallogeneic pregnancy, with $\mathrm{T}$ cell tolerance but humoral sensitization, raised the possibility that humoral sensitization might promote rejection and resistance to transplantation tolerance. Indeed, semiallogeneic PP recipients were resistant to $\mathrm{CoB} /$ DST-induced tolerance of fetus-matched HTx, and pretransplant FSA was mediating this resistance. These observations are consistent with our previous reports in virgin mice $(36,37)$ showing that adoptively transferred DSA into naive recipients was sufficient to mediate resistance to $\mathrm{CoB} / \mathrm{DST}$-induced tolerance to offspring-matched cardiac allografts. These observations, together with the resistance to tolerance occurring despite an overall increase in the numbers of $2 \mathrm{~W}: \mathrm{I}^{-\mathrm{A}^{\mathrm{b}}}$ Tregs, a lack in donor-specific $2 \mathrm{~W}: \mathrm{I}^{\mathrm{b}} \mathrm{A}^{\mathrm{T}} \mathrm{Tconv}$ and OVA: $\mathrm{K}^{\mathrm{b}} \mathrm{CD} 8^{+} \mathrm{T}$ cell accumulation, and the inability of PP T cells to produce IFN- $\gamma$ even in PP recipients rejecting F1 HTx, raised the possibility that PP T cells were tolerant to offspring-matched HTx, and it was humoral sensitization that was overriding pregnancy-mediated $\mathrm{T}$ cell tolerance. Consistent with this, fetus-matched heart allografts were spontaneously accepted by $\mathrm{PP} \mu \mathrm{KO}$ recipients that were deficient in B cells and antibodies.

The presence of PP B cells did not prevent the development of $\mathrm{T}$ cell tolerance during pregnancy, but their presence at the time of
HTx overrode $\mathrm{T}$ cell dysfunction and facilitated the acute rejection of offspring-matched HTx. Because PP sIgKO B cells were incapable of secreting antibodies, but were able to override $\mathrm{T}$ cell tolerance, we hypothesized that pregnancy-primed B cells functioned as antigen-presenting cells and/or provided the proinflammatory signals necessary in overriding dysfunction in PP T cells. Supporting the latter possibility, we and others have reported that proinflammatory cytokines such as type I IFN or IL-6 produced during bacterial or viral infections prevent the induction of $\mathrm{CoB}$-induced tolerance (44-47). While PP sIgKO B cells are sufficient to override pregnancy-induced T cell tolerance, FSA/DSA is also sufficient (Supplemental Figure 12), underscoring the formidable barriers imposed by humoral sensitization as a result of semiallogeneic pregnancies. Finally, it is unclear why PP B cells and FSA can override T cell tolerance to cardiac allografts, yet permit acceptance of semiallogeneic fetuses in subsequent pregnancies. Studies defining the mechanisms within the fetomaternal interface that provide additional layers of constraint on fetus-specific $\mathrm{T} / \mathrm{B}$ interactions and resistance to antibody-mediated damage and that are not accessible to the allograft, should provide critical insights.

As with allogeneic transplantation, a successful pregnancy must balance the need to limit pathogenic immune responses directed at the semiallogeneic fetus with the need to preserve protective immunity to infections in the mother, fetus, and neonate. The former is achieved through induction of potent immunomodulatory mechanisms at the fetomaternal interface, and these mechanisms can be detected systemically (48). For the latter, the production of maternal neutralizing antibodies and their passage to fetuses, neonates, and infants are critical for fetal protection from infections during the time when the immune system is immature (49). Maternal IgG crosses the syncytiotrophoblast barrier by binding to FcRn to provide passive immunity to the fetus and newborn, while nursing mothers transfer neutralizing antibodies via breastmilk, thus providing continued passive protection to the infant, especially in the event of new infections (50-52). We theorize that the evolutionary need to preserve protective humoral immunity during pregnancy and PP inadvertently allows for the development of FSA that are deleterious to offspring-matched allografts. That the presence of FSA does not prevent successful subsequent pregnancies underscores heritable trait selection for mechanisms at the maternofetal interface that mitigate the pathogenic effects of FSA, including the expression of complement regulatory proteins $(53,54)$. In contrast, protective $T$ cells generated in the mother cannot be similarly transferred, and in fact, when fetus-specific $\mathrm{T}$ cell responses develop unchecked in the absence of Tregs, preeclampsia or spontaneous abortion of the fetus occurs (55-57). As a result, we hypothesize that there are fewer constraints in the evolution of mechanisms for tolerizing fetus-specific $\mathrm{T}$ cell responses during pregnancy. Our studies demonstrate that these tolerance mechanisms extend to offspring-matched allografts, which are revealed when pregnancy-sensitized humoral responses are abrogated.

That antibody responses are preserved late in pregnancy and early PP is consistent with observations from a prospective, blinded trial of mothers receiving trivalent influenza vaccine in the third trimester of pregnancy that resulted in higher influenza-specific IgA levels in the breastmilk for at least 6 months PP. Furthermore, breastfed infants of influenza-vaccinated mothers had fewer episodes of respiratory illness in the first 6 months PP, which positively correlated with the extent of exclusive breastfeeding (58). Preserva- 
tion of humoral immunity during pregnancy may conversely have detrimental effects, as illustrated by reports of autoimmune disease exacerbation. Nelson et al. (59) reported that exposure to fetal DNA may trigger scleroderma, with disease incidence increasing in the years after childbearing. In addition, $15 \%-60 \%$ of pregnant women experience exacerbation in systemic lupus erythematosus, while 5\%-9\% develop PP autoimmune thyroiditis coincident with new onset of anti-thyroid peroxidase (anti-TPO) autoantibodies and with disease recurrence in $75 \%$ of women in subsequent pregnancies $(60,61)$. These observations suggest broader implications of preserved humoral immunity during and immediately after pregnancy with respect to health disparities for multigravid women.

In conclusion, our findings provide a potential theoretical framework for understanding immunity to semiallogeneic pregnancy and offspring-matched organ transplantation, where fetus-specific T cell dysfunction permits repeated successful allogeneic pregnancies and where humoral sensitization provides protective immunity to the mother and child, but becomes a barrier for allogeneic transplantation. Furthermore, the absence of FSA together with depletion of pregnancy-sensitized B cells at the time of offspring-matched allograft transplantation in PP recipients reveals the presence of $\mathrm{T}$ cell tolerance and spontaneous acceptance of offspring-matched allografts. These observations raise the intriguing possibility that multigravid recipients, through processes of infectious tolerance and linked suppression $(62,63)$, may be uniquely prone to developing tolerance to organs that share HLA antigens with offspring compared with males or nonparous women who have not developed fetal-specific $\mathrm{T}$ cell tolerance. Additionally, it has been reported that fetus-specific anti-HLA IgG disappears in approximately $50 \%$ of women at 2 years PP (64). It is therefore tantalizing to consider a therapeutic strategy involving $\mathrm{B}$ cell depletion in FSA-negative multigravid mothers for mitigating the sensitizing effects of pregnancy and revealing the tolerogenic effects of pregnancy to offspring-matched allografts.

\section{Methods}

Mice. Eight- to 12-week-old female C57BL/6 (B6, H-2 ${ }^{\mathrm{b}}$ ) mice were purchased from The Jackson Laboratory or Harlan Laboratories. Act-2W-OVA transgenic mice on a C57BL / 6 background (2W-OVA. C57BL/6) were a gift from James Moon (Massachusetts General Hospital, Harvard Medical School, Charlestown, Massachusetts, USA). Secretory IgM (Ighm) and AID (Aicda) double-knockout mice $\left(\mathrm{H}-2^{\mathrm{b}}, \operatorname{sIgKO}\right)$ mice were originally a gift from Frances E. Lund (38). B6.129S2-Igh-6tm1Cgn/J ( $\mu \mathrm{KO}$ ) mice were purchased from The Jackson Laboratory. Donor 2W-OVA.BALB/c mice were backcrossed from $2 \mathrm{~W}$-OVA.C57BL/ 6 mice for more than 10 generations. For mating, male 2W-OVA.BALB/c mice were introduced to virgin C57BL/6 females, and successfully mated mice were confirmed by a visualized copulation plug representing E0.5. Approximately $50 \%$ of F1 from this mating were confirmed to be $2 \mathrm{~W}$-OVA positive. In other experiments, male $2 \mathrm{~W}$-OVA.BALB/c were mated with female sIgKO or $\mu \mathrm{KO}$ mice.

Heart transplantation and $\mathrm{B}$ cell depletion. Heterotopic heart transplantations were performed as previously described (37), by grafting 2W-OVA.F1 hearts onto the inferior vena cava and aorta of female recipients. Tolerance (CoB/DST) was induced with a combination of anti-CD154 (MR1, Bio X Cell) at a dose of $500 \mu \mathrm{g}$ on day 0 (i.v.), and $250 \mu \mathrm{g}$ on days 7 and 14 (i.p.) after transplantation, in combina- tion with $2 \times 10^{7} \mathrm{HTx}$-matched spleen cells on day 0. CTLA-4Ig (Abatacept, Bristol-Myers Squibb) was used at a dose of $250 \mu \mathrm{g} /$ mouse (i.p.) on days 0, 2, 4, and 7 after HTx. Flank skin from 2W-OVA.F1 was transplanted onto C57BL/6 mice. For B cell depletion, sIgKO PP mice received $250 \mu \mathrm{g}$ anti-CD20 antibody (i.v.) (SA271G2, catalog 152104, BioLegend) on days -1 and 7 relative to HTx. Graft survival was assessed by palpation every other day, and the day of rejection was defined as the last day of detectable heartbeat.

$T$ and $B$ cell enrichment. Single-cell suspensions from spleens and pooled LNs (brachial, inguinal, and axillary) of sIgKO PP mice were prepared. The following biotinylated antibodies were used for B cell enrichment by negative selection: anti-CD4 (GK1.5, catalog 100404, BioLegend), anti-CD8a (53-6.7, catalog 100704, BioLegend), anti- $\gamma \delta \mathrm{T}-$ CR (eBioGL3, catalog 13-5711-85, Invitrogen), anti-F4/80 (BM8, cata$\log 123106$, BioLegend), anti-49b (DX5, catalog 108904, BioLegend), anti-NK1.1 (PK136, catalog 108704, Invitrogen), anti-CD11b (M1/70, catalog 101204, BioLegend), anti-CD11c (N418, catalog 117304, BioLegend), and anti-Ly-6G/Ly-6C (RB6-8C5, catalog 108404, BioLegend). These antibodies were incubated with cells for 20 minutes at $4^{\circ} \mathrm{C}$ followed by washing before incubation with streptavidin magnetic beads for 10 minutes at room temperature (catalog 88817, Thermo Scientific). Labeled cells were separated using a magnetic particle concentrator (Dynal, Invitrogen). Purity of B cells was determined to be $95 \%$ or more by post-sort flow cytometry (LSRII 4-12). In some experiments, lymphocytes were isolated by pooling murine spleen and LNs and $\mathrm{CD} 4^{+}$lymphocytes were enriched with the $\mathrm{CD} 4^{+} \mathrm{T}$ Cell Isolation Kit (Miltenyi Biotech). Enriched CD4 ${ }^{+}$cells were subjected to 45 minutes $2 \mathrm{~W}: \mathrm{IA}^{\mathrm{b}}$ tetramer staining at room temperature, followed by 30 minutes extracellular staining at room temperature. After fixation and permeabilization (eBioscience), cells were stained for intracellular markers at $4^{\circ} \mathrm{C}$ overnight. Samples were run on an LSR-II 4-12 flow cytometer (BD FACSDiva, version 8.0.2) or LSR Fortessa 4-15 HTS (BD FACSDiva, version 8.0.2), and data were analyzed using FlowJo software.

Cell harvest and tetramer staining for flow cytometry. Spleens and LNs were harvested and passed through a $40 \mu \mathrm{m}$ cell strainer (Corning, catalog 431750) followed by red blood cells being lysed by 2 minutes of incubation with ammonium chloride-potassium (ACK) lysis buffer (Quality Biological). Viable cells were enumerated by trypan blue exclusion on a hemocytometer, and cells were resuspended in $2 \%$ FBS in PBS. Approximately $10^{7}$ cells were stained with a fixable live/ dead stain (Aqua, Invitrogen) followed by tetramer staining. PE- and APC-conjugated 2W (EAWGALANWAVDSA):I-A ${ }^{\mathrm{b}}$ tetramer (NIH Tetramer Core Facility, Atlanta, Georgia, USA) and OVA (SIINFEKL): $\mathrm{H}-2 \mathrm{~K}^{\mathrm{b}}$ tetramer $(\mathrm{NIH})$ incubation were performed for 30 minutes at room temperature. Cells were then washed, and the following antibodies were added for surface staining at $4^{\circ} \mathrm{C}$ : $\mathrm{CD} 11 \mathrm{~b}$ (M1/70, catalog 101224, BioLegend), NK1.1(PK136, catalog 48-5941-82), Ter-119 (Ter119, catalog 48-5921-82, eBioscience), F4/80 (BM8, catalog 48-480182, Invitrogen), CD49b (DX5, catalog 485971-82, Invitrogen), CD11c (N418, catalog 48-0114-82), CD90.2 (53-2.1, catalog 47-0902-82, Invitrogen), CD4 (RM4-5, catalog 48-0042-82, eBioscience), CD3 (17A2, catalog 48-0032-82, Invitrogen), CD8 (53-6.7, catalog 48-008182, eBioscience), CD4 (RM4-5, catalog 563106, BD Biosciences), CD44 (IM7, catalog 560570, BD Biosciences), FR4 (eBio12A5, catalog 25-5445-82, eBioscience), CD73 (TY/11.8, catalog 127215, BioLegend), CD8 (53-6.7, catalog 100706, BioLegend), CD44 (IM7, catalog 563114, BD Biosciences), CD62L (MEL-14, catalog 563252, BD Biosciences), 
PD-1 (RMP1-30, catalog 109110, BD BioLegend), CD25 (PC61, catalog 102015, BioLegend), GITR (DTA-1, catalog 126315, BioLegend), B220 (RA3-6B2, catalog 563103, BD Biosciences), CD19 (eBio1D3, catalog 48-0193-82, Invitrogen), CD138 (281-2, catalog 142516, BioLegend), IgD (11-26c.2a, catalog 405716, BioLegend), Fas (Jo2, catalog 557653, BD Biosciences), and T and B cell activation antigen (GL7, Cat.553666, BD Biosciences). For intracellular staining, samples were fixed with Foxp3 Fix/Perm buffer set according to the manufacturer's instruction (eBioscience). Samples were then intracellularly stained with Ki67 (B56, catalog 561283, BD Biosciences), Foxp3 (FJK-16s, catalog 53-5773-82, Invitrogen), and CTLA-4 (UC10-4F10-11, catalog 565778, BD Biosciences). Samples were run on an LSR-II 4-12 flow cytometer (BD FACSDiva 8.0.2) or LSR Fortessa 4-15 HTS (BD FACSDiva 8.0.2), and data were analyzed using FlowJo software.

In vitro stimulation for IFN- $\gamma$ staining. Splenocyte stimulators from TCR- $\beta^{-/-}$C57BL/ 6 mice or 2W-OVA.F1 mice were prepared, and their red blood cells were lysed with ACK lysing buffer (Quality Biological). F1 splenocytes were incubated with anti-CD90.2 (53-2.1, catalog $553000, \mathrm{BD}$ Biosciences) to deplete $\mathrm{T}$ cells, followed by 2 consecutive incubations with rabbit complement (CL3441-S50, Cedarlane) at $37^{\circ} \mathrm{C} ; 60 \times 10^{6}$ splenocytes of each group from stimulator and responder were then incubated overnight with $5 \mu \mathrm{g} / \mathrm{mL}$ LPS. The following day, $1 \times 10^{6}$ responder cells were incubated with $5 \times 10^{6}$ stimulators in triplicate in a 96-well plate (catalog CLS 3595 Corning) at $37^{\circ} \mathrm{C}$ overnight. Next, $1 \mu \mathrm{g}$ of Golgi Plug (catalog 51-2301KZ, BD Biosciences) was added and incubated for an additional 6 hours at $37^{\circ} \mathrm{C}$. Extracellular staining was performed in an ice-water bath; then cells were fixed with BD Cytofix/Cytoperm according to the manufacturer's instructions (catalog 51-2090KZ, BD Biosciences) and stained for intracellular IFN- $\gamma$ (XMG1.2, catalog 505810, BioLegend). Cell samples were run on an LSR-II 4-12 flow cytometer (BD FACSDiva, version 8.0.2) or an LSR Fortessa 4-15 HTS (BD FACSDiva, version 8.0.2).

DSA determination. To determine titers of DSA in the serum of recipients, $5 \times 10^{5}$ to $1 \times 10^{6} 2$ W.OVA.BALB/c or OVA.C57BL/6 splenocytes were incubated for 30 minutes at $4^{\circ} \mathrm{C}$ with $5 \mu \mathrm{L}$ of serum from recipient mice. Cells were then washed and incubated with anti-CD19 (1D3, catalog 550992, BD Biosciences) and goat anti-mouse IgG $(\mathrm{H}+\mathrm{L})$ (catalog 1031-02, Southern Biotech), mouse IgG1 (catalog 0102-09, Southern Biotech), mouse IgG2b (catalog 0104-19, Southern Biotech), goat antimouse IgG2c (catalog 1079-02, Southern Biotech), and mouse IgG3 (catalog 0105-17, Southern Biotech) for 30 minutes at $4^{\circ} \mathrm{C}$. Mean fluorescence intensity of the CD19-negative cells that were $\operatorname{IgG}$ positive were measured by flow cytometry LSR-II 4-12 (BD FACSDiva, version 8.0.2).

Histology. Heart graft tissue was removed and fixed in $10 \%$ formalin for 48 hours prior to transfer to $70 \%$ ethanol for storage. Tissue was embedded in paraffin, sections were cut and stained by $\mathrm{H} \& \mathrm{E}$, and immunohistochemistry stains for CD4 (catalog 14-9766-80, Invitrogen) and CD8 (catalog 14-0808-82, Invitrogen) were performed. Slides were then scanned using the CRI Panoramic Whole Slide Scanner (PerkinElmer). Grafts were scored in a single blind manner on a 5-point scale, with 0 to 5 points given for gross histopathological abnormalities, scarring, decellularization, and extent of mononuclear cell infiltration.

Statistics. Statistical significance analyses were performed using GraphPad Prism, version 8. Sample sizes of 5 to 10 or more animals per experiment were chosen to ensure adequate power. Graft-survival significance was assessed using a Kaplan-Meier/Mantel-Cox log-rank test. $P$ values of less than 0.05 were considered significant. When the same control groups were presented across multiple figures, the outcomes achieved were concatenated from multiple experiments performed over the course of the entire study and demonstrating similar outcomes. To calculate differences between experimental animals, we used Kruskal-Wallis test with Dunn's post hoc test for pairwise multiple comparisons and Mann-Whitney unpaired $t$ test.

Study approval. All animal experiments were approved by the Institutional Animal Care and Use Committee at the University of Chicago and adhered to the standards of the NIH Guide for the Care and Use of Laboratory Animals (National Academies Press, 2011).

\section{Author contributions}

DJ, MSA, JMP, and JSY conducted the remaining experiments. All analyzed their data and assisted in generating the figures. DY performed heart transplants, while GC provided sIgKO mice and advice on how to work with these mice. MLA provided critical feedback on study design and edited the manuscript, and ASC designed the study and cowrote the manuscript. All authors provided feedback and approved the manuscript. The order of the co-first authors, ANS, DKVT and SHWK, is listed based on their relative contributions to the study.

\section{Acknowledgments}

We thank the flow cytometry core and animal facilities at the University of Chicago for their assistance. This work was supported in part by grants (R01AI142747, P01AI097113) from the National Institute of Allergy and Infectious Diseases (NIAID), NIH. JSY was supported by an American Heart Association Enduring Hearts Fellowship grant (15POST25700452) and an NIH Respiratory Biology Training grant (T32 HL07605). ANS was a recipient of the 2017 American Society of Transplant Surgeons Resident Scientist Scholarship. MHC tetramers were provided by the NIH Tetramer Core Facility (contract HHSN272201300006C). The Flow Cytometry Core facility is supported by a Cancer Center Support Grant (P30CA014599).

Address correspondence to: Anita S. Chong, Department of Surgery, University of Chicago, 5841 S. Maryland Ave., Chicago, Illinois 60637, USA. Phone: 773.702.5521; Email: achong@surgery. bsd.uchicago.edu.
1. Erlebacher A. Immunology of the maternal-fetal interface. Annu Rev Immunol. 2013;31:387-411.

2. Förger F, Villiger PM. Immunological adaptations in pregnancy that modulate rheumatoid arthritis disease activity. Nat Rev Rheumatol. 2020;16(2):113-122.

3. PrabhuDas M, et al. Immune mechanisms at the maternal-fetal interface: perspectives and challenges. Nat Immunol. 2015;16(4):328-334.
4. Nancy P, Tagliani E, Tay CS, Asp P, Levy DE, Erlebacher A. Chemokine gene silencing in decidual stromal cells limits $\mathrm{T}$ cell access to the maternal-fetal interface. Science. 2012;336(6086):1317-1321.

5. Aluvihare VR, Kallikourdis M, Betz AG. Regulatory $\mathrm{T}$ cells mediate maternal tolerance to the fetus. Nat Immunol. 2004;5(3):266-271.

6. Vacca P, et al. Analysis of natural killer cells isolated from human decidua: Evidence that 2B4 (CD244) functions as an inhibitory receptor and blocks NK-cell function. Blood. 2006;108(13):4078-4085.

7. Tripathi S, Guleria I. Biomarkers in fetomaternal tolerance. Clin Lab Med. 2019;39(1):145-156.

8. Ander SE, Diamond MS, Coyne CB. Immune responses at the maternal-fetal interface. Sci Immunol. 2019;4(31):eaat6114.

9. Rosenblum MD, Way SS, Abbas AK. Regulatory T 
cell memory. Nat Rev Immunol. 2016;16(2):90-101.

10. Rowe JH, Ertelt JM, Xin L, Way SS. Pregnancy imprints regulatory memory that sustains anergy to fetal antigen. Nature. 2012;490(7418):102-106.

11. Barton BM, Xu R, Wherry EJ, Porrett PM. Pregnancy promotes tolerance to future offspring by programming selective dysfunction in long-lived maternal $\mathrm{T}$ cells. JLeukoc Biol. 2017;101(4):975-987.

12. Hench PS. The ameliorating effect of pregnancy on chronic atrophic (infectious rheumatoid) arthritis, fibrositis, intermittent hydraarthritis. Mayo Clin Proc. 1938;13:161-167.

13. Bell SC, Billington WD. Major anti-paternal alloantibody induced by murine pregnancy is non-complement-fixing IgG1. Nature. 1980;288(5789):387-388

14. Dillon DM, Cunningham C, Melvin WT, Catto GR. Characterisation of the humoral immune response during murine pregnancy. J Reprod Immunol. 1988;14(1):59-72.

15. Innes A, Power DA, Cunningham C, Dillon D, Catto GR. The alloantibody response to semiallogeneic pregnancy in the rat. I. Alloantibodies in sera and placental eluates directed to RT1A antigens. Transplantation. 1988;46(3):409-413.

16. Masson $E$, et al. Incidence and risk factors of anti-HLA immunization after pregnancy. Hum Immunol. 2013;74(8):946-951.

17. Vilches M, Nieto A. Analysis of pregnancy-induced anti-HLA antibodies using luminex platform. Transplant Proc. 2015;47(9):2608-2610.

18. Porrett PM. Biologic mechanisms and clinical consequences of pregnancy alloimmunization. Am J Transplant. 2018;18(5):1059-1067.

19. Hönger G, Fornaro I, Granado C, Tiercy JM, Hösli I, Schaub S. Frequency and determinants of pregnancy-induced child-specific sensitization. Am J Transplant. 2013;13(3):746-753.

20. Redfield RR, et al. The mode of sensitization and its influence on allograft outcomes in highly sensitized kidney transplant recipients. Nephrol Dial Transplant. 2016;31(10):1746-1753.

21. Moon JJ, et al. Quantitative impact of thymic selection on Foxp3+ and Foxp3- subsets of self-peptide/ MHC class II-specific CD4+ T cells. Proc Natl Acad SciUS A. 2011;108(35):14602-14607.

22. Kalekar LA, et al. CD4(+) T cell anergy prevents autoimmunity and generates regulatory $\mathrm{T}$ cell precursors. Nat Immunol. 2016;17(3):304-314.

23. Chen J, Wang Q, Yin D, Vu V, Sciammas R, Chong AS. Cutting edge: CTLA-4Ig inhibits memory B cell responses and promotes allograft survival in sensitized recipients. JImmunol. 2015;195(9):4069-4073.

24. Chen J, et al. Reversing endogenous alloreactive $B$ cell GC responses with anti-CD154 or CTLA4Ig. Am J Transplant. 2013;13(9):2280-22892.

25. Yang J, et al. Tracing Donor-MHC class II reactive $\mathrm{B}$ cells in mouse cardiac transplantation: delayed CTLA4-Ig treatment prevents memory alloreactive B-cell generation. Transplantation. 2016;100(8):1683-1691.

26. Erlebacher A, Vencato D, Price KA, Zhang D, Glimcher LH. Constraints in antigen presentation severely restrict $\mathrm{T}$ cell recognition of the allogeneic fetus. J Clin Invest. 2007;117(5):1399-1411.

27. Moldenhauer LM, Diener KR, Thring DM, Brown MP, Hayball JD, Robertson SA. Cross-presentation of male seminal fluid antigens elicits $\mathrm{T}$ cell activation to initiate the female immune response to pregnancy. JImmunol. 2009;182(12):8080-8093.

28. Rodríguez-Perea AL, Arcia ED, Rueda CM, Velilla PA. Phenotypical characterization of regulatory T cells in humans and rodents. Clin Exp Immunol. 2016;185(3):281-291.

29. Wing JB, Tay C, Sakaguchi S. Control of regulatory T cells by co-signal molecules. Adv Exp Med Biol. 2019;1189:179-210.

30. Campbell DJ, Koch MA. Phenotypical and functional specialization of FOXP3+ regulatory T cells. Nat Rev Immunol. 2011;11(2):119-130.

31. Wing K, et al. CTLA-4 control over Foxp3+ regulatory T cell function. Science. 2008;322(5899):271-275.

32. Kalekar LA, Mueller DL. Relationship between $\mathrm{CD} 4$ regulatory $\mathrm{T}$ cells and anergy in vivo. J Immunol. 2017;198(7):2527-2533.

33. Deaglio $S$, et al. Adenosine generation catalyzed by $\mathrm{CD} 39$ and $\mathrm{CD} 73$ expressed on regulatory $\mathrm{T}$ cells mediates immune suppression. J Exp Med. 2007;204(6):1257-1265.

34. Lenschow DJ, et al. Long-term survival of xenogeneic pancreatic islet grafts induced by CTLA4lg. Science. 1992;257(5071):789-792.

35. Vincenti F, et al. Costimulation blockade with belatacept in renal transplantation. $\mathrm{N}$ EnglJ Med. 2005;353(8):770-781.

36. Burns AM, Chong AS. Alloantibodies prevent the induction of transplantation tolerance by enhancing alloreactive $\mathrm{T}$ cell priming. J Immunol. 2011;186(1):214-221.

37. Burns AM, et al. Memory alloreactive B cells and alloantibodies prevent anti-CD154-mediated allograft acceptance. JImmunol. 2009;182(3):1314-1324.

38. Kumazaki K, Tirosh B, Maehr R, Boes M, Honjo T, Ploegh HL. AID-/-mus-/- mice are agammaglobulinemic and fail to maintain B220-CD138+ plasma cells. JImmunol. 2007;178(4):2192-2203.

39. Zeng $Q$, et al. B cells mediate chronic allograft rejection independently of antibody production. JClin Invest. 2014;124(3):1052-1056.

40. Van rood JJ, Eernisse JG, Van leeuwen A. Leucocyte antibodies in sera from pregnant women. Nature. 1958;181(4625):1735-1736.

41. Patel R, Terasaki PI. Significance of the positive crossmatch test in kidney transplantation. $N$ Engl JMed. 1969;280(14):735-739.

42. Guleria I, et al. A critical role for the programmed death ligand 1 in fetomaternal tolerance. JExp Med. 2005;202(2):231-237.

43. Kussel L, et al. Longitudinal assessment of HLA and MIC-A antibodies in uneventful pregnancies and pregnancies complicated by preeclampsia or gestational diabetes. Sci Rep. 2017;7(1):13524.

44. Dangi A, Zhang L, Zhang X, Luo X. Murine CMV induces type 1 IFN that impairs differentiation of MDSCs critical for transplantation tolerance. Blood Adv. 2018;2(6):669-680.

45. Ahmed EB, Wang T, Daniels M, Alegre ML, Chong AS. IL-6 induced by Staphylococcus aureus infection prevents the induction of skin allograft acceptance in mice. Am J Transplant. 2011;11(5):936-946.

46. Wang T, et al. Prevention of allograft tolerance by bacterial infection with Listeria monocytogenes. JImmunol. 2008;180(9):5991-5999.

47. Thornley TB, et al. Type 1 IFN mediates cross- talk between innate and adaptive immunity that abrogates transplantation tolerance. J Immunol. 2007;179(10):6620-6629.

48. Erlebacher A. Mechanisms of T cell tolerance towards the allogeneic fetus. Nat Rev Immunol. 2013;13(1):23-33.

49. Niewiesk S. Maternal antibodies: clinical significance, mechanism of interference with immune responses, and possible vaccination strategies. Front Immunol. 2014;5:446.

50. Kohler PF, Farr RS. Elevation of cord over maternal IgG immunoglobulin: evidence for an active placental IgG transport. Nature. 1966;210(5040):1070-1071.

51. Wilcox CR, Holder B, Jones CE. Factors affecting the FcRn-mediated transplacental transfer of antibodies and implications for vaccination in pregnancy. Front Immunol. 2017;8:1294.

52. Kristoffersen EK. Placental Fc receptors and the transfer of maternal IgG. Transfus Med Rev. 2000;14(3):234-243.

53. Hansen VL, Miller RD. Evidence for regulation of the complement system during pregnancy being ancient and conserved in mammals. Dev Comp Immunol. 2020;104:103562.

54. Xu C, Mao D, Holers VM, Palanca B, Cheng AM, Molina H. A critical role for murine complement regulator crry in fetomaternal tolerance. Science. 2000;287(5452):498-501.

55. Rowe JH, Ertelt JM, Aguilera MN, Farrar MA, Way SS. Foxp3(+) regulatory T cell expansion required for sustaining pregnancy compromises host defense against prenatal bacterial pathogens. Cell Host Microbe. 2011;10(1):54-64.

56. Sasaki Y, Sakai M, Miyazaki S, Higuma S, Shiozaki A, Saito S. Decidual and peripheral blood $\mathrm{CD} 4+\mathrm{CD} 25+$ regulatory $\mathrm{T}$ cells in early pregnancy subjects and spontaneous abortion cases. Mol Hum Reprod. 2004;10(5):347-353.

57. Prins JR, et al. Preeclampsia is associated with lower percentages of regulatory $\mathrm{T}$ cells in maternal blood. Hypertens Pregnancy. 2009;28(3):300-311.

58. Schlaudecker EP, et al. IgA and neutralizing antibodies to influenza a virus in human milk: a randomized trial of antenatal influenza immunization. PLoS One. 2013;8(8):e70867.

59. Nelson JL, et al. Microchimerism and HLA-compatible relationships of pregnancy in scleroderma. Lancet. 1998;351(9102):559-562.

60. Adams Waldorf KM, Nelson JL. Autoimmune disease during pregnancy and the microchimerism legacy of pregnancy. Immunol Invest. 2008;37(5):631-644.

61. Lazarus JH. Epidemiology and prevention of thyroid disease in pregnancy. Thyroid. 2002;12(10):861-865.

62. Cobbold SP, Adams E, Nolan KF, Regateiro FS, Waldmann H. Connecting the mechanisms of T-cell regulation: dendritic cells as the missing link. Immunol Rev. 2010;236:203-218.

63. Qin S, et al. "Infectious" transplantation tolerance. Science. 1993;259(5097): 974-977.

64. van Kampen CA, Versteeg-vd Voort Maarschalk MF, Langerak-Langerak J, Roelen DL, Claas FH. Kinetics of the pregnancy-induced humoral and cellular immune response against the paternal HLA class I antigens of the child. Hum Immunol. 2002;63(6):452-458. 